2017-04-15

Observations of nearshore infragravity

wave dynamics under high energy swell

and wind-wave conditions

\author{
Mikhalenko, Natalia
}

http://hdl.handle.net/10026.1/9317

10.1016/j.csr.2017.02.010

Coastal Engineering

Elsevier BV

All content in PEARL is protected by copyright law. Author manuscripts are made available in accordance with publisher policies. Please cite only the published version using the details provided on the item record or document. In the absence of an open licence (e.g. Creative Commons), permissions for further reuse of content should be sought from the publisher or author. 


\title{
Observations of nearshore infragravity wave dynamics under high energy swell and wind-wave conditions
}

\author{
Kris Inch ${ }^{*}$, Mark Davidson, Gerd Masselink and Paul Russell
}

School of Marine Science and Engineering, Plymouth University, Drake Circus, Plymouth, Devon PL4 8AA. United Kingdom.

kris.inch@plymouth.ac.uk, M.Davidson@plymouth.ac.uk, gerd.masselink@plymouth.ac.uk, P.Russell@plymouth.ac.uk

* Corresponding author. Tel.: +44 (0)1752 586100; Fax: +44 (0)1752 586101; Email: kris.inch@plymouth.ac.uk (Kris Inch)

\begin{abstract}
Infragravity waves $(0.005-0.04 \mathrm{~Hz})$ can dominate the water motion close to shore on low sloping beaches and play a significant role in beach and dune erosion. A new field data set of water surface elevation at 15 cross-shore locations on a dissipative, fetch-unlimited beach is analysed to investigate the forcing and surf zone behaviour of infragravity waves during a wide range of offshore wave conditions $\left(H_{o}=0.38-3.88 \mathrm{~m} ; T_{p}=6-20 \mathrm{~s}\right)$. Infragravity waves approach the shore as bound waves lagging slightly $(\sim 4 \mathrm{~s})$ behind the short wave $(0.04$ $-0.33 \mathrm{~Hz}$ ) envelope and are released in the surf zone as free waves. Infragravity wave heights of up to $1 \mathrm{~m}$ are measured close to shore and are best predicted using an offshore forcing parameter that represents the short wave energy flux $\left(H_{o}^{2} T_{p}\right)$. Considerable infragravity dissipation is observed in the surf zone and dissipation increases with offshore wave energy. Dissipation is highly frequency-dependant and a frequency-domain Complex Empirical Orthogonal Function analysis reveals (quasi-)standing waves at frequencies < $0.017 \mathrm{~Hz}$, but an increasingly progressive wave pattern at higher frequencies with reflection coefficients $<0.1$, indicative of more than $90 \%$ dissipation. Much of the observed dissipation occurs very close to shore and the dependence of the reflection coefficient on a normalised bed slope parameter implies that energy at high infragravity frequencies is dissipated by wave breaking, since these frequencies fit into a mild sloping regime. This is supported by the results of bispectral analysis which show predominantly infragravity-infragravity interactions
\end{abstract}


in shallow water and the development of infragravity harmonics indicative of steepening and eventual breaking of the infragravity waves.

Keywords: Infragravity waves, bound waves, surf zone, reflection, dissipation, frequencydependant.

\section{Introduction}

Infragravity waves, or long waves, are low frequency waves (typically $0.005-0.05 \mathrm{~Hz}$ ) that make up a significant proportion of the total energy in the inner surf zone. Unlike sea-swell waves, which break and become saturated in the surf zone (Thornton and Guza, 1982), infragravity wave height has been observed to increase shoreward from up to a few $\mathrm{cm}$ in deep water (e.g., Aucan and Ardhuin, 2013; Crawford et al., 2015) to over $1 \mathrm{~m}$ close to shore (e.g., Guza and Thornton, 1982; Ruessink et al., 1998; Senechal et al., 2011; Fiedler et al., 2015). As a result, infragravity waves play an important role in beach and dune erosion (e.g., Russell, 1993; Van Thiel de Vries et al., 2008; Roelvink et al., 2009). Infragravity wave height in the nearshore, or at the shoreline as runup, has frequently been shown to be positively correlated with offshore wave height (e.g., Guza and Thornton, 1982; Ruessink et al., 1998; Ruggiero et al., 2004; De Bakker et al., 2014). However, the relationship between offshore wave period and infragravity waves, particularly their behaviour in the surf zone, has received less attention.

A stronger correlation between nearshore infragravity energy and offshore energy in the swell frequency band $(0.04-0.14 \mathrm{~Hz})$ than that in the sea frequency band $(0.14-0.33 \mathrm{~Hz})$ was observed by Elgar et al. (1992) and Ruessink (1998). The findings of Stockdon et al. (2006) indicate that a parameter accounting for both offshore wave height and wave period is crucial in explaining the variability in infragravity runup and observe a strong relationship with $\left(H_{o} L_{o}\right)^{1 / 2}$, where $H_{o}$ is offshore wave height and $L_{o}$ is the deep water wavelength. These findings were validated by Senechal et al. (2011) who found that infragravity wave runup during extreme storm conditions has considerably less scatter when correlated with $\left(H_{o} L_{o}\right)^{1 / 2}$ than with $H_{o}$ only. Contardo and Symonds (2013) report a $30 \%$ stronger infragravity wave height response to long period incident swell than to short period wind-sea during low-moderate forcing conditions. Furthermore, Ardhuin et al. (2014) found the 
infragravity wave height in deep water to be strongly correlated with a parameter that includes both wave height and mean wave period and also found the largest infragravity wave heights to correspond with the largest mean period rather than the largest sea-swell wave height.

Two main mechanisms exist for the generation of infragravity waves. Biésel (1952), followed by Longuet-Higgins and Stewart (1962) and Hasselmann (1962), demonstrated theoretically that infragravity waves can originate well seaward of the surf zone by difference interactions between pairs of waves at sea-swell frequencies. This excites a group-bound, second-order wave with the same wavelength and period as the wave group, but is $180^{\circ}$ out of phase. In the surf zone, where the short wave height becomes depth-limited and wave groupiness is significantly reduced, bound infragravity waves may be released to propagate shoreward as free waves (e.g., Masselink, 1995). However, Baldock (2012) argues, based on LonguetHiggins and Stewart (1962), that bound infragravity waves will be progressively released when the short waves are in shallow water and the bound wave satisfies the free wave dispersion relationship, which can occur seaward or shoreward of the short wave breakpoint. An alternative generation mechanism, proposed by Symonds et al. (1982), is the time-varying breakpoint theory in which infragravity waves arise from oscillations in wave set-up/down as a result of the fluctuating breakpoint of different size wave groups. These breakpoint forced long waves have the same frequency as the wave groups and radiate away from the breakpoint in both the shoreward and seaward direction. The dominant generation mechanism is likely to depend on beach slope (Battjes et al., 2004) and short wave steepness (Baldock and Huntley, 2002; Baldock, 2012). Mild sloping beaches are conducive to bound infragravity waves which shoal strongly seaward of the breakpoint and have small wavelengths relative to the surf zone width. Whereas, breakpoint forced infragravity waves are more dominant on steep beaches where the wavelength of the short wave groups is large compared with the surf zone width.

It was long believed that infragravity waves reflect almost entirely from the shore giving rise to a cross-shore quasi-standing wave structure (Guza and Thornton, 1985). More recently, however, considerable infragravity wave dissipation close to shore has been observed in a number of field (e.g., Ruessink, 1998; Sheremet et al., 2002; Henderson et al., 2006; Guedes et al., 2013; De Bakker et al., 2014; Fiedler et al., 2015), laboratory (e.g., Battjes et al., 2004; Van Dongeren et al., 2007; De Bakker et al., 2015), and numerical modelling (e.g., Ruju et al., 
2012; De Bakker et al., 2016) studies. Furthermore, a number of studies have observed runup saturation extending into the infragravity band on dissipative beaches and under highly energetic wave conditions (e.g., Ruggiero et al., 2004; Senechal et al. 2011; Guedes et al., 2013).

Several mechanisms have been proposed in the literature to explain the observed decay of infragravity wave energy close to shore. Henderson and Bowen (2002) suggested bottom friction as a dominant dissipation mechanism. However, unlike in coral reef environments where the bottom surface is comparatively rough (Pomeroy et al., 2012; Van Dongeren et al., 2013), bottom friction on sandy beaches has since been deemed a secondary dissipation mechanism at best (e.g., Henderson et al., 2006; Van Dongeren et al., 2007; De Bakker et al., 2014). Henderson et al. (2006) and Thomson et al. (2006), and several studies since, have shown that infragravity energy loss can result from non-linear energy transfers back to seaswell frequencies through triad interactions. This process is most important on steeper beaches or in surf zone depths of more than $\sim 1 \mathrm{~m}$ where sea-swell energy exceeds infragravity energy, but less so on gently sloping beaches where infragravity energy dominates in the inner surf zone and triad interactions tend to be between infragravity frequencies only (Guedes et al., 2013; De Bakker et al., 2014, 2015, 2016). These infragravity-infragravity interactions allow for the steepening of the infragravity wave which culminates in its breaking and thus considerable energy loss close to shore (e.g., Battjes et al., 2004; Van Dongeren et al., 2007; Lin and Hwung, 2012; De Bakker et al., 2014). Numerical modelling by Ruju et al. (2012) suggests that the observed infragravity wave energy loss can result from a combination of non-linear energy transfer to sea-swell frequencies in the outer surf zone and wave breaking closer to shore.

Based on bichromatic wave experiments, Van Dongeren et al. (2007) showed that the amplitude reflection coefficient $R$ of infragravity waves at the shoreline is related to a normalized bed slope parameter $\beta_{H}$ defined as

$$
\beta_{H}=\frac{\beta T}{2 \pi} \sqrt{\frac{g}{H^{+}}}
$$

where $\beta$ is bed slope, $T$ is the infragravity wave period, $g$ is gravitational acceleration, and $\mathrm{H}^{+}$is the height of the incoming infragravity wave. The normalized bed slope parameter is 
based on the premise that a given beach slope will have a higher effective steepness for low frequency (long) waves than it will for high frequency (short) waves. Van Dongeren et al. (2007) observed a transition at $\beta_{H} \approx 1.25$, below which waves experience a mild sloping regime and dissipate due to wave breaking, and above which waves experience a steep sloping regime and reflect with minimal dissipation. Using field data from a dissipative beach, De Bakker et al. (2014) observed a more gradual transition from mild to steep sloping regime occurring at $\beta_{H} \approx 3$, whereas numerical modelling by De Bakker et al. (2016) showed this transition occurring at $\beta_{H} \approx 4$.

The objective of this paper is to investigate the dependence of infragravity waves on offshore forcing parameters, with particular attention given to the magnitude and spatial variation of the infragravity energy flux in the surf zone during contrasting swell and wind-wave conditions. In doing so, this contribution extends the work of De Bakker et al. (2014) and other field studies that have largely been undertaken on low fetch coastlines and/or during low-moderate energy conditions. New field observations are presented of infragravity waves on a high energy, dissipative, fetch-unlimited beach under a wide variety of offshore wave conditions. Data collection methods and analysis techniques are described in Section 2. Results of infragravity wave forcing, propagation and reflection are presented in Section 3. These results are placed into context with previous findings in Section 4, and summarised in Section 5 .

\section{Methodology}

\subsection{Field site and data collection}

Data were collected for 33 consecutive tidal cycles from 7 to 24 November 2014 at Perranporth Beach, Cornwall, UK (Fig. 1). Perranporth, situated at the southern end of Perran Sands, is a macrotidal, dissipative beach with a semi-diurnal tidal regime and a mean spring tidal range of $6.1 \mathrm{~m}$. The intertidal region has an average cross-shore length of $500 \mathrm{~m}$ and a longshore extent of $1.2 \mathrm{~km}$. Perranporth is a relatively straight beach facing west-northwest so is fully exposed to the dominant westerly wave approach, receiving both Atlantic swell and locally generated wind waves. The beach is characterised by a low-gradient $(\beta \approx 0.012$ over the intertidal region), concave profile composed of medium sand $\left(D_{50}=0.30 \mathrm{~mm}\right)$. Most 
of the intertidal region is relatively featureless and alongshore homogeneous; however, well pronounced bar-rip morphology is exposed during spring low tides (Poate et al., 2014).

Perranporth's relatively featureless profile, along with its cross-shore dominance and exposure to a wide range of swell and wind waves, make it an excellent site for studying infragravity wave behaviour under different levels of offshore forcing.
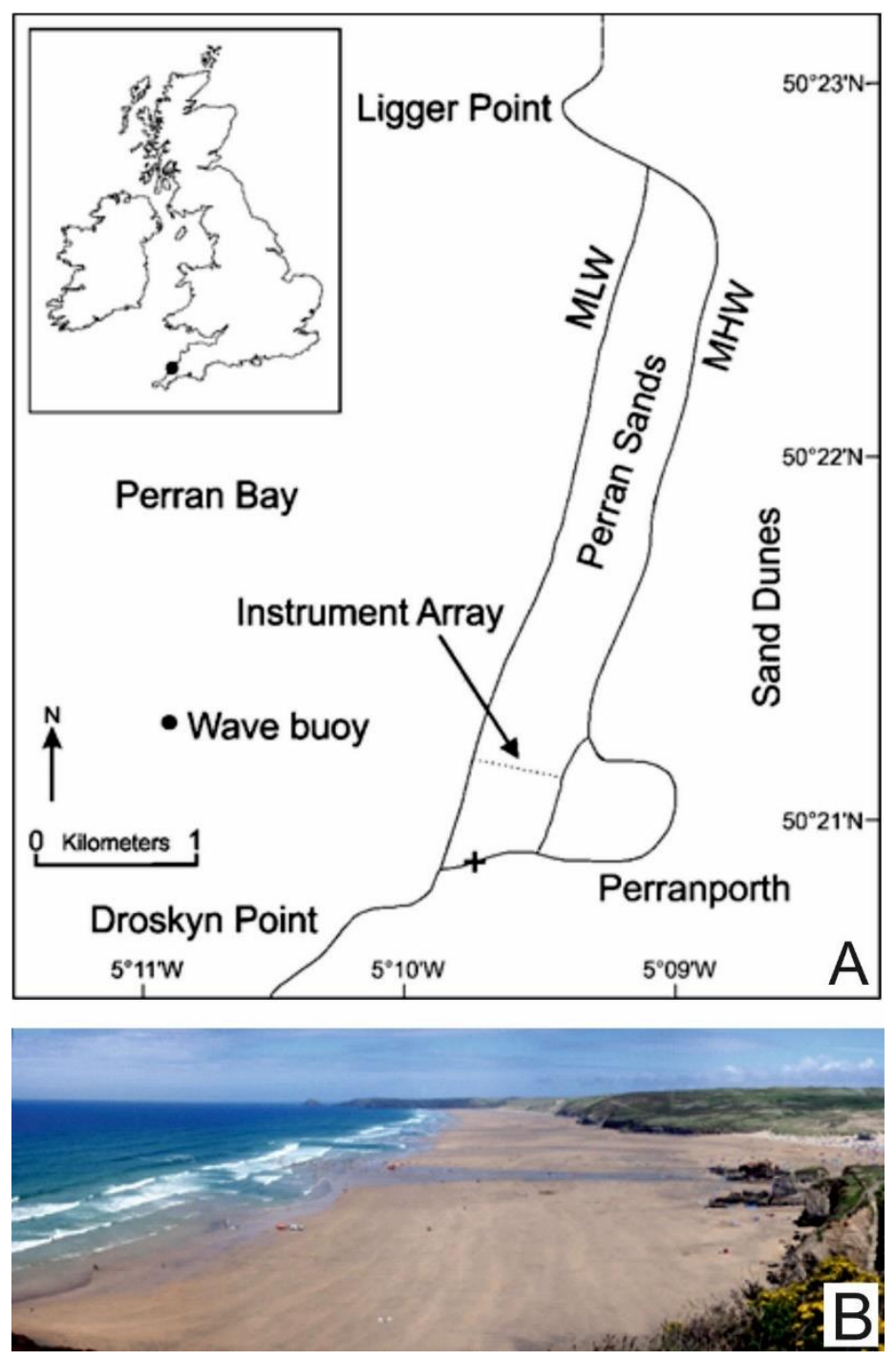

Fig. 1. Location map of Perranporth Beach, UK (A). Photograph of Perranporth Beach (B) taken facing north from the location of the + symbol in (A).

Pressure observations were logged continuously at $4 \mathrm{~Hz}$ by 15 in situ pressure sensors. The sensors were situated in a cross-shore array spanning 372 m (Fig. 2); 13 were located between the mean spring high and mean spring low tide lines and 2 were located slightly above the mean spring high tide line to capture inner surf zone data during periods of particularly energetic wave forcing that are typical for the time of year. The pressure sensors 
were securely attached to screw in ground anchors or small lengths of scaffolding and buried so that the pressure sensor was $\sim 0.1 \mathrm{~m}$ below the bed. The pressure sensors were buried in order to be less intrusive and to avoid corruption of the pressure signal caused by dynamic pressure variations from accelerating and decelerating flows. In addition to the buried pressure sensors, a rig equipped with a co-located pressure sensor and an acoustic Doppler velocimeter sampling $0.2 \mathrm{~m}$ above the bed, both logging at $4 \mathrm{~Hz}$, was deployed for 10 selected tides during the latter half of the study period. The instrument transect was measured on alternate low tides using real time kinematic GPS ( $\pm 0.03 \mathrm{~m}$ accuracy) and experienced little variability throughout the field experiment. The elevation of the instruments was measured at every low tide and adjustments were made, as necessary, to keep the instruments at their intended elevations with respect to the bed level.

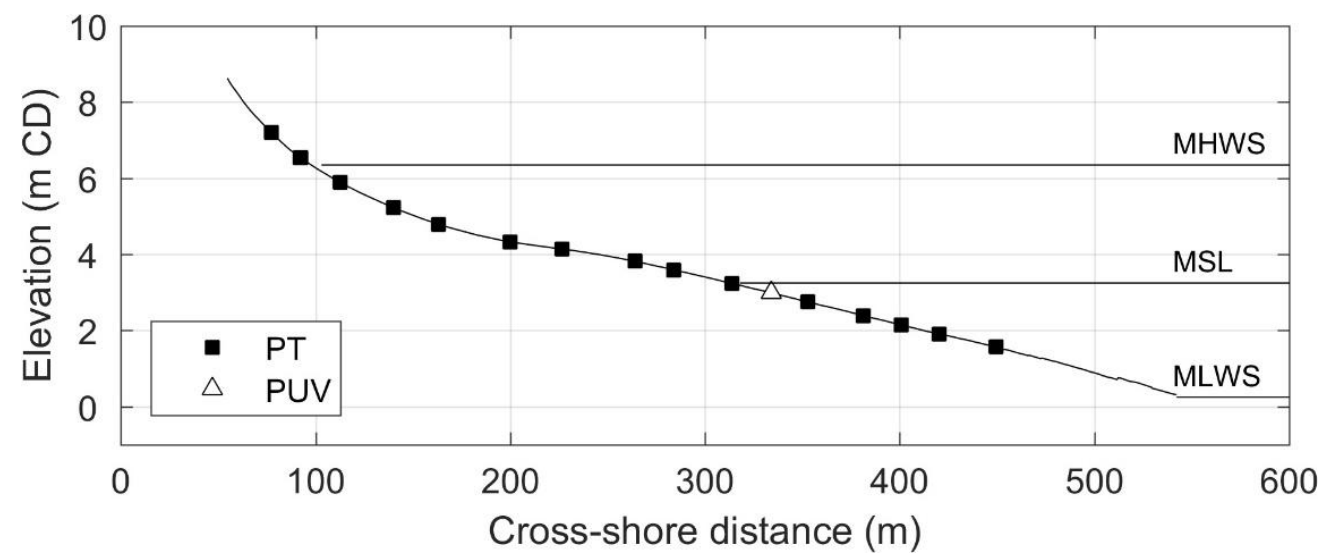

Fig. 2. Mean beach profile during the field experiment showing the positions of the buried pressure sensors and the co-located pressure and velocity rig. Elevation is relative to chart datum (CD). Horizontal lines indicate mean sea level (MSL), mean high water springs (MHWS), and mean low water springs (MLWS).

\subsection{Data processing and analysis}

The results presented in this paper are based on $\sim 34$ minute blocks of data (8192 data points) centred around every high tide. Wave statistics (height and period) were relatively constant during these periods and tide induced changes in water level were minimal. Data that were found to be intermittently wet and dry (i.e., swash) were discarded. Pressure data were converted to water surface elevation with a frequency-domain attenuation correction for water depth using linear wave theory. Poroelastic theory was used to correct for the small amount of attenuation due to the pressure sensors being buried (Raubenheimer et al., 1998). 
Auto-spectra were computed using linearly detrended, Hanning-windowed, 50\% overlapping segments of 1024 data points, giving 27 degrees of freedom (Nutall, 1971) and a frequency resolution $d f$ of $0.0039 \mathrm{~Hz}$. Significant wave heights for the infragravity $(0.005-0.04 \mathrm{~Hz})$ and sea-swell $(0.04-0.33 \mathrm{~Hz})$ frequency bands $\left(H_{\text {inf }}\right.$ and $H_{s S}$, respectively) were calculated as

$$
H_{\text {inf }}=4 \sqrt{\int_{0.005 \mathrm{~Hz}}^{0.04 \mathrm{~Hz}} E(f) d f}
$$

and

$$
H_{s S}=4 \sqrt{\int_{0.04 \mathrm{~Hz}}^{0.33 \mathrm{~Hz}} E(f) d f}
$$

where $E$ is the spectral density at frequency $f$. The lower limit of the infragravity band was set at $0.005 \mathrm{~Hz}$ to ensure that any tidal signal was removed from the data. Additionally, the spectral density at frequencies below this cut-off was not well correlated with the offshore sea-swell energy, indicating that there may be another mechanism forcing these very low frequency waves. To avoid the inclusion of sea-swell energy within the infragravity band during the longest period tides, the upper limit of the infragravity band is set at $0.04 \mathrm{~Hz}$. The high frequency cut-off of $0.33 \mathrm{~Hz}$ for the sea-swell band corresponds to a depth attenuation of $\sim 80 \%$ at the most seaward pressure sensor during spring high tides, thus higher frequencies could not be corrected confidently. Infragravity and sea-swell water surface elevation time series ( $\eta_{\text {inf }}$ and $\eta_{s s}$, respectively) were calculated by applying a frequency-domain filter to the original time series.

The spectra were decomposed into incoming and outgoing components $\left(E^{+}(f)\right.$ and $E^{-}(f)$, respectively) using the array method of Gaillard et al. (1980). This method uses the spectra from a sub-array of three cross-shore pressure sensors to estimate the mean incoming and outgoing spectra at the centre of that sub-array. Modifications were made to the original technique to account for wave shoaling over a sloping bed and a noise correction was performed following Inch et al. (2017). Significant incoming and outgoing infragravity wave 
heights $\left(H^{+}\right.$and $H^{-}$, respectively) were calculated following Eq. 2 and replacing $E$ with $E^{+}$ and $E^{-}$, respectively. The incoming and outgoing spectra were also used to calculate corresponding frequency-dependant energy fluxes $\left(F^{+}(f)\right.$ and $F^{-}(f)$, respectively) as

$$
F^{ \pm}(f)=E^{ \pm}(f) \sqrt{g h}
$$

where $h$ is water depth. Frequency-dependant reflection coefficients $R^{2}(f)$ were calculated as the ratio of $F^{-}(f)$ to $F^{+}(f)$. Bulk infragravity energy fluxes $F^{ \pm}$and reflection coefficients $R^{2}$ were estimated by integrating over the infragravity frequency range where

$$
F^{ \pm}=\int_{0.005 \mathrm{~Hz}}^{0.04 \mathrm{~Hz}} F^{ \pm}(f) d f
$$

and

$$
R^{2}=F^{-} / F^{+}
$$

The focal point of this paper is cross-shore infragravity dynamics. Whilst it is not possible to evaluate the importance of alongshore infragravity motion using only pressure measurements in a cross-shore alignment, analysis of the available co-located pressure and velocity data provides confidence that alongshore infragravity dynamics are relatively insignificant in the data. Firstly, the alongshore infragravity velocity variance is always $<50 \%$ of the cross-shore infragravity velocity variance during the 10 available tides, with an average ( \pm one standard deviation) of $33 \% \pm 7 \%$. Secondly, shear wave contributions to the total infragravity velocity variance, calculated following Lippmann et al. (1999), are $25 \% \pm 11 \%$. These values are well below the thresholds defined by Henderson et al. (2006) and De Bakker et al. (2014). These findings regarding alongshore motions are supported by those of Miles and Thorpe (2015) who observed tidally modulated mean alongshore currents at Perranporth which were close to zero at high tide.

\subsection{Experimental conditions}


Offshore wave conditions were measured at $1.28 \mathrm{~Hz}$ by a Datawell Directional Waverider buoy located off Perranporth in approximately $14 \mathrm{~m}$ water depth relative to chart datum. A wide range of offshore wave conditions were present during the study period (Fig. 3). Significant wave height $H_{o}$ ranged from 0.38 to $3.88 \mathrm{~m}$ with a mean value of $1.84 \mathrm{~m}$. There were 5 occasions during the study period during which $H_{o}$ exceeded $2 \mathrm{~m}$ for 12 hours or more, and 2 periods of 12 hours during which $H_{o}$ remained below $0.5 \mathrm{~m}$. Spectral peak period $T_{p}$ varied between 6 and $20 \mathrm{~s}$ with a mean value of $12.5 \mathrm{~s}$. The experiment spanned a springspring tidal cycle with spring and neap tidal ranges of around $6.7 \mathrm{~m}$ and $2.2 \mathrm{~m}$, respectively. Wave direction at the buoy was tidally modulated and typically ranged between $20^{\circ}$ south and $15^{\circ}$ north of shore normal (mean $=4^{\circ}$ south).

The average breaker coefficient $\gamma_{b}$, defined as $H_{S S} / h$ at the onset of short wave breaking, was 0.42 for the high tides that included sensors measuring outside of the surf zone (11 tides). These tides were selected from visual observations of the data, with the shoaling region being identified as a clear shoreward increase in $H_{s S}$, characteristic of shoaling waves outside the surf zone. Using $\gamma_{b}$, data are given a normalized surf zone position $h / h_{b}$, where $h_{b}$ is the water depth at the short wave break point defined as $h_{b}=H_{b} / \gamma_{b}$, where $H_{b}$ is the breaking wave height. $H_{b}$ is calculated by shoaling $H_{o}$ shoreward from the wave buoy using linear wave theory to the depth at which the shoaled wave height $\approx \gamma_{b} h$. A total of $82.4 \%$ of the data analysed corresponded to $h / h_{b}$ values $<1$, indicating that the majority of data were collected from within the surf zone. Furthermore, during particularly small wave conditions and/or spring tides, the most seaward sensor obtained measurements 2-3 surf zone widths from the shoreline. While $\gamma_{b}$ corresponds to the breaking of the largest short waves, in the saturated inner surf zone, where all short waves are broken and $H_{S S}$ is depth limited, the ratio of $H_{s S}$ to $h$ (often referred to as $\gamma$ ) rises to a fairly constant value of $\sim 0.52$. 

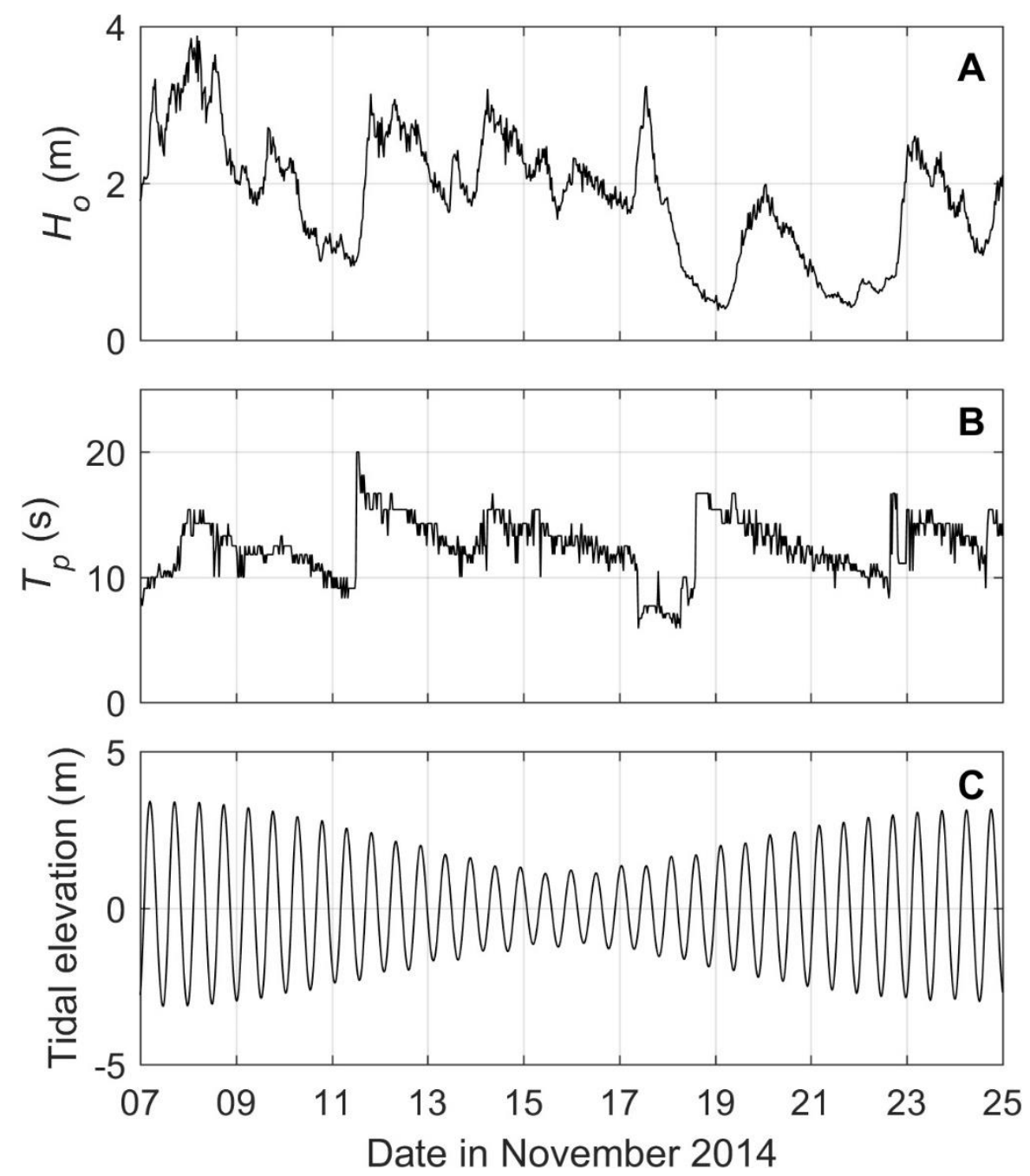

Fig. 3. Offshore wave conditions during the study period, measured by a Datawell

Directional Waverider buoy in approximately $14 \mathrm{~m}$ water depth relative to chart datum.

Significant wave height $H_{o}(\mathrm{~A})$, spectral peak period $T_{p}(\mathrm{~B})$, and tidal elevation relative to mean sea level (C).

\section{Results}

\subsection{Basic hydrodynamic statistics}

A summary of the hydrodynamic statistics recorded by the pressure sensors during the study period is given in Table 1 . The maximum $H_{\text {inf }}$ measured was $1.02 \mathrm{~m}$ at the most shoreward sensor $(h=0.52 \mathrm{~m})$ on $8^{\text {th }}$ November with a $H_{0}$ of $3.51 \mathrm{~m}$ and a $T_{p}$ of $13.8 \mathrm{~s}$. This also corresponds to the time and location at which infragravity energy was most dominant, accounting for $92.9 \%$ of the total wave variance. It was during this tide that the maximum 
values of $\mathrm{H}^{+}$and $\mathrm{H}^{-}$were also measured, with a maximum $\mathrm{H}^{+}$of $0.70 \mathrm{~m}$ measured at $h=$ $3.25 \mathrm{~m}$, and a maximum $H^{-}$of $0.48 \mathrm{~m}$ occurring closer to shore at $h=1.14 \mathrm{~m}$. In contrast, the minimum $H_{\text {inf }}$ of $0.05 \mathrm{~m}$ was measured at the most seaward sensor $(h=4.36 \mathrm{~m})$ on $22^{\text {nd }}$ November when $H_{o}=0.65 \mathrm{~m}$ and $T_{p}=9.3 \mathrm{~s}$. Here, seaward of the surf zone, infragravity variance accounted for only $0.06 \%$ of the total wave variance and it was during this tide that the lowest $H^{+}$value of $0.04 \mathrm{~m}$ was measured at $h=4.21 \mathrm{~m}$. With the breaking of sea-swell waves, the ratio of infragravity to sea-swell variance increased shoreward and averaged 2.52 at the shallowest sensor where infragravity variance exceeded sea-swell variance for $69.7 \%$ of the 33 high tides. Infragravity amplification, the ratio of infragravity wave height at the shallowest sensor relative to the deepest sensor, ranged from 0.84 to 3.30 with the strongest amplifications typically occurring when $H_{o}$ and $T_{p}$ were lower.

Table 1. Overview of basic hydrodynamic statistics (recorded during all tides and at all locations).

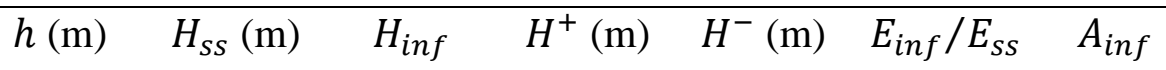

(m)

\begin{tabular}{lccccccc}
\hline Mean & 2.09 & 1.07 & 0.41 & 0.34 & 0.15 & 0.45 & 1.50 \\
Standard Deviation & 1.13 & 0.56 & 0.20 & 0.17 & 0.09 & 1.16 & 0.62 \\
Minimum & 0.20 & 0.25 & 0.05 & 0.04 & 0.01 & 0.01 & 0.84 \\
Maximum & 4.83 & 3.03 & 1.02 & 0.70 & 0.48 & 13.08 & 3.30 \\
\hline
\end{tabular}

$h=$ water depth, $H_{s s}=$ sea-swell wave height, $H_{\text {inf }}=$ total infragravity wave height, $H^{+}=$ incoming infragravity wave height, $H^{-}=$outgoing infragravity wave height, $E_{\text {inf }} / E_{S S}=$ ratio of infragravity to sea-swell variance, $A_{\text {inf }}=$ infragravity amplification.

\subsection{Generation and forcing}

With the range of forcing conditions experienced during the study period, as well as the changing tidal range, the instruments were measuring at different locations relative to the surf zone during each tide. In order to have a consistent value representing the infragravity wave height with which to relate to the offshore forcing conditions, here $H_{\text {inf }}$ is averaged over the range $0<h / h_{b}<0.33$ (i.e., inner one third of the surf zone) for each tide. This corresponds to between 2 and 7 measurement locations. 
Fig. 4a shows a strong positive correlation between $H_{\text {inf }}$ and $H_{o}$ with the coefficient of determination $r^{2}$ associated with the best-fit linear line revealing that $79 \%$ of the variability in $H_{\text {inf }}$ is determined by $H_{o}$ (all $r^{2}$ values reported herein are significant at the $95 \%$ level). Replacing $H_{o}$ with $H_{\text {swell }}$ (offshore wave height in the frequency band $0.04<f<0.14 \mathrm{~Hz}$ ) removes the influence of short period sea waves and yields an improved $r^{2}$ of 0.89 (Fig. 4b). Conversely, $H_{\text {sea }}$ (offshore wave height in the frequency band $0.14<f<0.33 \mathrm{~Hz}$ ) provides a much weaker prediction of $H_{\text {inf }}$ with an $r^{2}$ of 0.28 (not shown). The transition from $H_{\text {swell }}$ to $H_{\text {sea }}$ at $f=0.14 \mathrm{~Hz}$ was chosen following Elgar et al. (1992) and Ruessink (1998).

Using $\left(H_{o} L_{o}\right)^{1 / 2}$ as the independent variable in the linear regression to account for wave period (following Stockdon et al., 2006; Senechal et al., 2011; Fiedler et al., 2015) reduces the scatter seen in Fig. 4 a with an $r^{2}$ of 0.89 (not shown); the same accuracy as using $H_{\text {swell }}$. However, the strongest prediction of $H_{\text {inf }}$ is achieved by using $H_{o}^{2} T_{p}$ to represent the offshore forcing (Fig. 4c) and this yields an $r^{2}$ of 0.93 . This parameter has greater physical justification than $\left(H_{o} L_{o}\right)^{1 / 2}$ as it is proportional to the offshore energy flux.

Infragravity saturation, where $H_{\text {inf }}$ ceases to increase despite further increases in offshore forcing, is not observed in any of the linear regression models. A summary of the regression coefficients, coefficients of determination, and RMS errors from fitting $H_{\text {inf }}$ with various offshore parameters is given in Table 2 . 

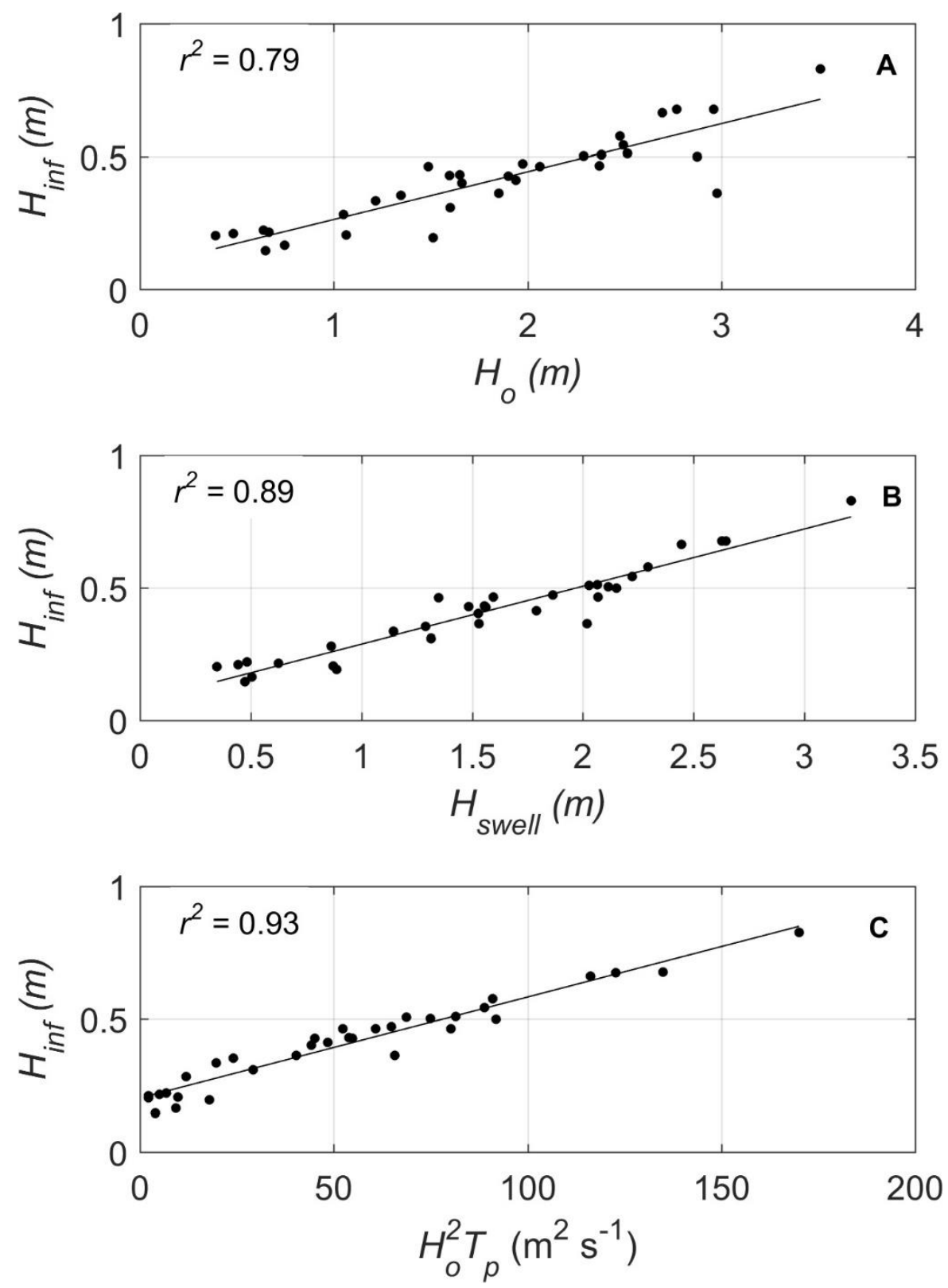

Fig. 4. Infragravity wave height $H_{\text {inf }}$ for $0<h / h_{b}<0.33$ versus offshore significant wave height $H_{o}(\mathrm{~A})$, offshore significant wave height in the swell frequency band $H_{\text {swell }}(\mathrm{B})$, and $H_{o}^{2} T_{p}(\mathrm{C})$. Black lines are best-fit linear regression lines with coefficients of determination given on the figure and regression coefficients given in Table 2.

Table 2. Regression parameters relating to linear fits between $H_{\text {inf }}$ and various offshore forcing parameters. All coefficients of determination $r^{2}$ are significant at the $95 \%$ level.

\begin{tabular}{cccccc}
\hline $\begin{array}{c}\text { Quantity } \\
\text { modelled }\end{array}$ & Model input & Slope $m$ & Intercept $b$ & $\begin{array}{c}\text { Coefficient of } \\
\text { determination } r^{2}\end{array}$ & RMSE (cm) \\
\hline$H_{\text {inf }}$ & $H_{o}$ & 0.18 & 0.08 & 0.79 & 6.7 \\
\hline
\end{tabular}




\begin{tabular}{lccccc}
\hline$H_{\text {inf }}$ & $H_{\text {swell }}$ & 0.22 & 0.07 & 0.89 & 4.5 \\
$H_{\text {inf }}$ & $H_{\text {sea }}$ & 0.19 & 0.25 & 0.28 & 14.4 \\
$H_{\text {inf }}$ & $T_{p}$ & 0.03 & 0.03 & 0.19 & 15.3 \\
$H_{\text {inf }}$ & $\left(H_{o} L_{o}\right)^{1 / 2}$ & 0.02 & 0.00 & 0.89 & 4.6 \\
$H_{\text {inf }}$ & $H_{o}^{2} T_{p}$ & 0.004 & 0.20 & 0.93 & 4.2 \\
\hline
\end{tabular}

A stronger infragravity response to swell than sea has been reported by others (e.g., Elgar et al., 1992; Okihiro et al., 1992) and is consistent with bound wave theory (Longuet-Higgins and Stewart, 1962; Hasselmann, 1962), given the dissipative nature of the beach. This is investigated further by performing a cross-correlation between the short wave envelope at the most seaward sensor and the infragravity time series at all locations for the 11 tides during which data were collected outside of the surf zone (i.e., $h / h_{b}>1$ ). The short wave envelope $A(t)$ was calculated following List (1991) as

$$
A(t)=\frac{\pi}{2}\left|\eta_{s s}(t)\right|_{\text {low }}
$$

where $t$ is time, $\eta_{s s}$ is the linearly detrended sea-swell time series, subscript low indicates a low pass filter of frequency $0.04 \mathrm{~Hz}$, and || represents absolute value. The resulting short wave envelope reflects the modulation with time of the sea-swell wave amplitudes. If the dominant source of infragravity energy is bound waves, then the cross-correlation coefficient at zero time lag $r^{0}$ should go to -1 offshore of the surf zone because the short wave envelope and the bound infragravity waves are $180^{\circ}$ out of phase. The $95 \%$ confidence intervals on cross-correlation coefficients, calculated as outlined in Garrett and Toulany (1981), are around \pm 0.08 .

All of the tides show clear evidence of bound waves at the most seaward sensor with values of $r^{0}$ significantly less than 0 . However, the strongest negative correlations of between -0.31 and -0.49 do not occur at zero time lag but at a lag of between 1.8 and $7.0 \mathrm{~s}$ (mean $=4.1 \mathrm{~s}$ ). This implies that the trough of the bound infragravity wave is lagging behind the crest of the short wave envelope. 
An example of the cross-correlations between the short wave envelope at the most seaward sensor and the infragravity time series at every shoreward location is shown in Fig. 5 for tide $7\left(H_{o}=1.05 \mathrm{~m}, T_{p}=10.8 \mathrm{~s}\right)$. At the most seaward location, the trough of the bound infragravity wave is lagged $3 \mathrm{~s}$ behind the crest of the short wave envelope and propagates shoreward at the group speed $C_{g}$, which in the present dataset $\approx \sqrt{g h}$, as shown by the bar of strong negative (blue) correlation. The correlation weakens very close to shore and the bar of negative correlation associated with the reflected infragravity wave, which agrees well with the shallow water wave speed $\sqrt{g h}$, is weaker than that of the incoming infragravity wave. This is most likely due to strong dissipation, as shown in the following section, but could also be related to the presence of a breakpoint forced infragravity wave that is positively correlated to the short wave envelope. However, a breakpoint forced infragravity wave should also generate a negatively correlated set-down wave radiating seaward of the surf zone, which is not clearly shown. The pattern shown in Fig. 5 is consistent across the 11 tides with data collected seaward of the surf zone.

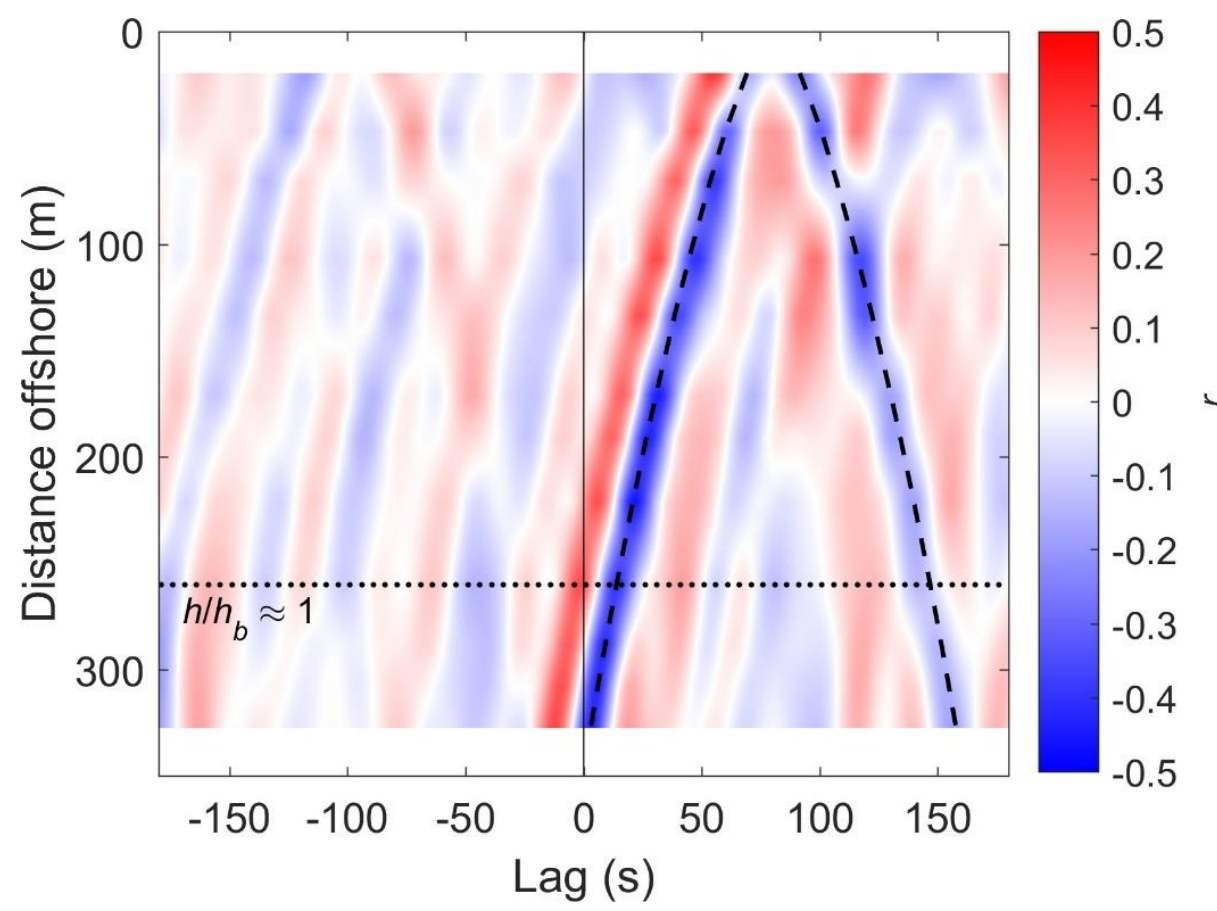

Fig. 5. Cross-correlation between the wave group envelope at the most seaward sensor and the infragravity wave time series at all locations during tide $7\left(H_{o}=1.05 \mathrm{~m}, T_{p}=10.8 \mathrm{~s}\right)$. The dashed black line is the predicted time lag for an incoming and outgoing wave propagating at $\sqrt{g h}$. The solid black line represents a time lag of $0 \mathrm{~s}$ and the horizontal dotted line shows the location of the short wave breakpoint at $h / h_{b} \approx 1$. Red indicates positive correlations and 
blue indicate negative correlations.

\subsection{Propagation, dissipation and reflection}

To investigate the spatial trend in infragravity wave propagation and dissipation across all tides, Fig. 6a shows $F^{+}$normalised by the mean value $\overline{F^{+}}$for every tide as a function of $h / h_{b}$. As can be seen, normalised values of $F^{+}$outside of the surf zone generally show an increasing trend towards the short wave breakpoint suggesting that infragravity waves are gaining energy. This increase continues into the surf zone until $h / h_{b} \approx 0.7$ where a clear, rapid decrease towards the shoreline begins. This decrease, consistent with infragravity dissipation, appears to accelerate slightly when $h / h_{b}$ becomes less than $\sim 0.3$. Fig. $6 \mathrm{~b}$ shows the correlation coefficient at zero lag time lag between the short wave envelope and the infragravity time series at all locations during all tides. It is clear that the switch from infragravity growth to dissipation at $h / h_{b} \approx 0.7$ coincides with a change in $r^{0}$ from negative to positive. The shift away from a negative correlation implies that the bound infragravity waves are being released as the short waves break and loose their group structure. Positive correlations in the inner surf zone imply that the largest short waves are propagating on the crests of the infragravity waves whilst the smaller short waves propagate in the infragravity wave troughs. This occurs as the infragravity wave crests increase the local water depth allowing larger short waves to prevail and restoring some groupiness, though now in phase with the infragravity wave. The grouped nature of the short waves can be investigated by calculating the groupiness factor. The groupiness factor $G F$, proposed by List (1991), provides a normalised value for the groupiness of the short wave envelope and is calculated as

$$
G F=\frac{\sqrt{2 v a r[A(t)]}}{\bar{A}(t)}
$$

where var is the variance and the overbar symbolises the mean. Fig. $6 \mathrm{c}$ shows a decrease in the groupiness factor starting at the short wave breakpoint and reaching a minimum in the middle of the surf zone, before increasing close to shore to levels similar to those outside of the surf zone. 
This modulation of short wave height by infragravity waves is further demonstrated in Fig. 7 which displays example sea-swell time series from three normalised surf zone locations during tide $27\left(H_{o}=0.67 \mathrm{~m}, T_{p}=11.4 \mathrm{~s}\right)$. Outside of the surf zone at $h / h_{b}=1.24$ (Fig. 7a) groups of short waves occur predominantly where there are infragravity wave troughs (cool colours) such as at $60 \mathrm{~s}, 170 \mathrm{~s}$, and $270 \mathrm{~s}$. At $h / h_{b}=0.68$ waves are in the transition zone where groupiness is reduced and the correlation between the short wave envelope and the infragravity time series is neither predominantly positive nor negative. Here the short wave time series displays no clear groups or relationship with the infragravity waves (Fig. 7b). However, the time series at $h / h_{b}=0.18$ shows the presence of wave groups, though now consisting of fewer waves, and these groups correspond to infragravity wave crests (warm colours) such as at 75 s, $200 \mathrm{~s}$, and $340 \mathrm{~s}$ (Fig. 7c). A detailed study of short wave modulation by infragravity waves using laboratory data is provided by Tissier et al. (2015).
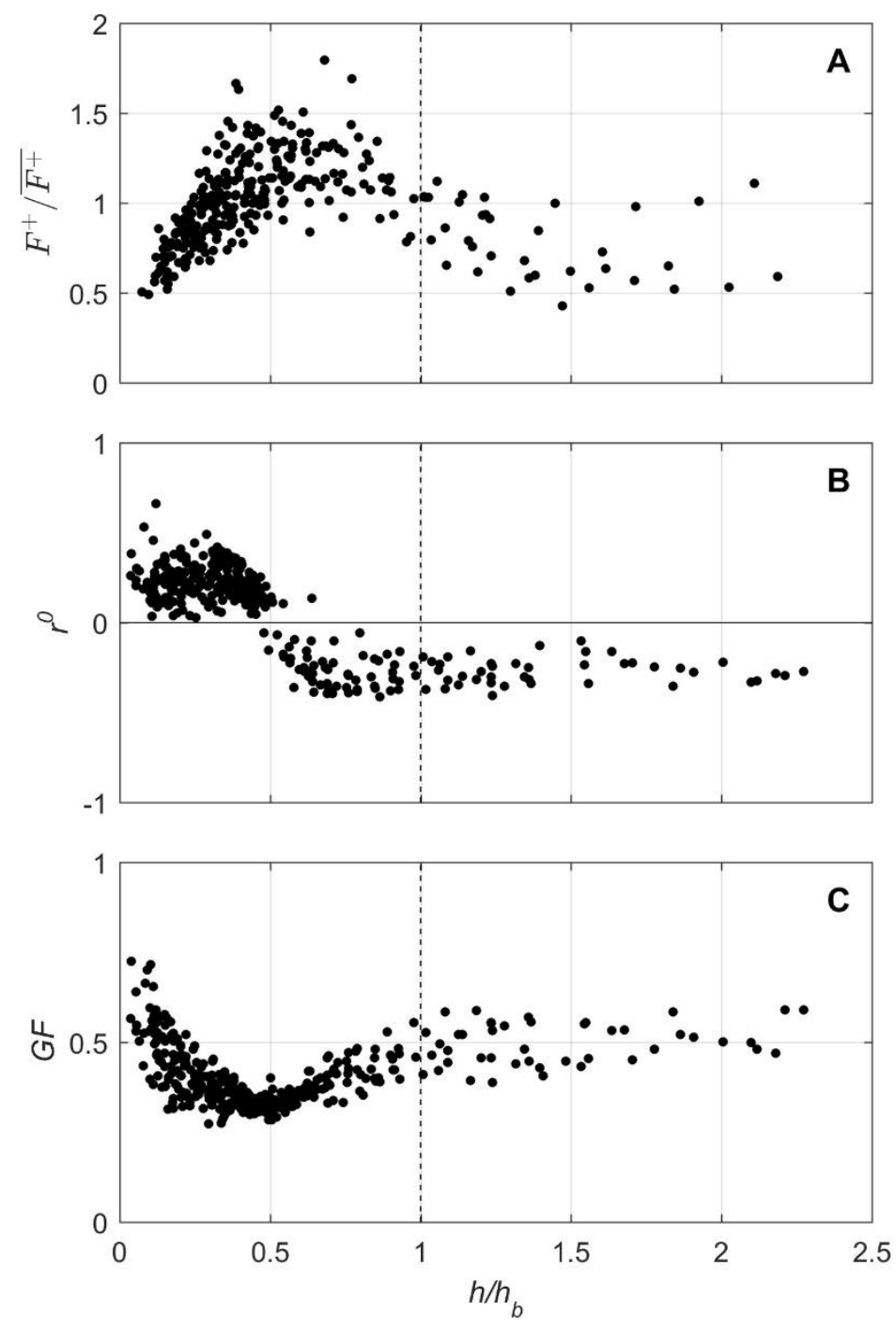
Fig. 6. Bulk incoming infragravity energy flux $\left(F^{+}\right)$normalised by the mean value $\left(\overline{F^{+}}\right)$for each tide (A), correlation coefficient at zero time lag $r^{0}$ between the wave group envelope and the infragravity time series (B), and groupiness factor $G F(\mathrm{C})$, versus normalised surf zone width $h / h_{b}$ for all locations during all tides. Dashed vertical lines indicate the seaward limit of the surf zone at $h / h_{b}=1$. Only $r^{0}$ values significant at the $95 \%$ level are shown in (B).
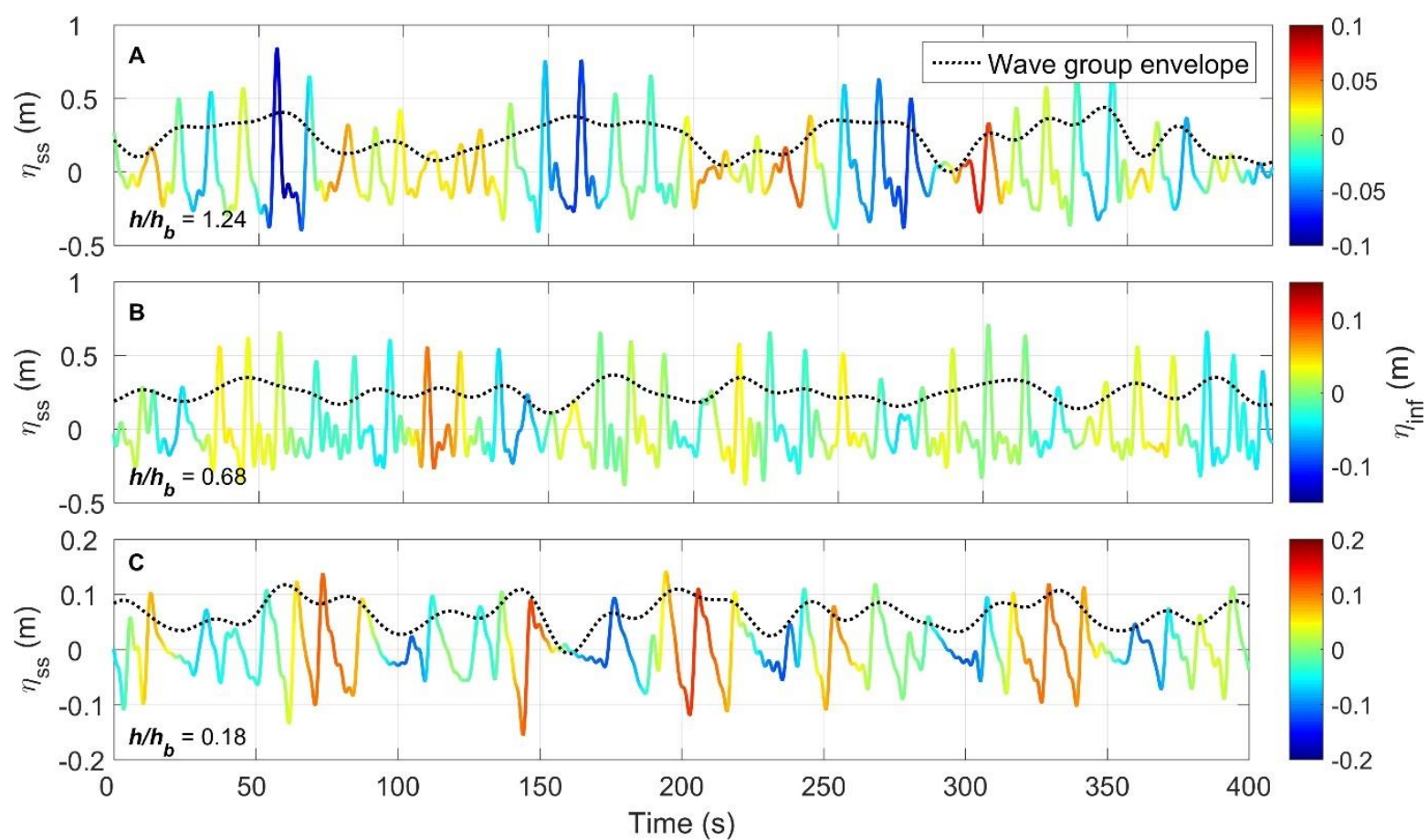

Fig. 7. Example sea-swell time series $\eta_{s s}$ from tide $27\left(H_{o}=0.67 \mathrm{~m}, T_{p}=11.4 \mathrm{~s}\right)$ at three normalized surf zone $h / h_{b}$ locations; $1.24(\mathrm{~A}), 0.68(\mathrm{~B})$, and $0.18(\mathrm{C})$. The dotted black line is the wave group envelope. Colour represents the infragravity water surface elevation $\eta_{\text {inf }}$ with warm colours indicating infragravity wave crests and cool colours indicating infragravity wave troughs. Note the different axis scales.

To further examine the propagation and transformation of infragravity waves and the influence of offshore forcing, three individual tides are investigated in detail. The level of offshore forcing, characterised by $H_{o}^{2} T_{p}$, varies considerably between the tides. This variability is not due to differences in $H_{o}$, which is $\sim 3 \mathrm{~m}$ during each tide, but rather by variations in $T_{p}$. The purpose of selecting these particular tides is to accentuate the effect that offshore wave period has on infragravity wave characteristics. A summary of the environmental parameters for each tide is given in Table 3. 
Table 3. Summary of environmental parameters during tides 10, 1, and 20.

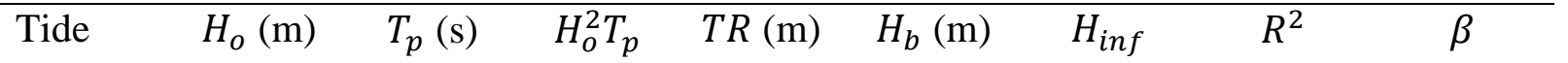

No.

\begin{tabular}{lcccccccc}
\hline 10 & 2.96 & 15.4 & 134.7 & 4.40 & 3.27 & 0.87 & 0.32 & 0.0319 \\
1 & 2.88 & 11.1 & 92.3 & 6.68 & 3.12 & 0.63 & 0.43 & 0.0447 \\
20 & 2.99 & 7.4 & 66.2 & 3.05 & 3.04 & 0.29 & 0.28 & 0.0188 \\
\hline
\end{tabular}

$H_{o}=$ offshore significant wave height, $T_{p}=$ offshore peak wave period, $T R=$ tidal range, $H_{b}$ = breaking wave height, $H_{\text {inf }}=$ infragravity significant wave height at the shoreline, $R^{2}=$ bulk infragravity reflection coefficient the shoreline, $\beta=$ swash zone beach slope. Note the similarity in $H_{o}$ for each tide but widely varying $T_{p}$.

To illustrate the difference in offshore forcing between the three tides, and its influence on infragravity energy levels in the surf zone, Fig. 8 shows the offshore wave spectra at the wave buoy and in the surf zone at $h \approx 2 \mathrm{~m}$. The offshore wave spectrum for tide 10 shows a large, narrow-banded peak typical of long period swell, with little energy at frequencies $>0.1 \mathrm{~Hz}$. This develops into a large, narrow infragravity peak in the surf zone at $f=0.0117 \mathrm{~Hz}$ (85 s) which dominates the surf zone spectrum. In contrast, the peak in the offshore wave spectrum for tide 20 straddles the boundary between swell and sea frequencies, with very little energy at frequencies $<0.1 \mathrm{~Hz}$. The surf zone spectrum for tide 20 shows very low levels of infragravity energy and, of the three tides, it is the only one with swell and sea peaks exceeding those in the infragravity band. The offshore spectrum for tide 1 sits somewhat in the middle of tides 10 and 20, with its primary peak in the swell band at $f=0.0900 \mathrm{~Hz}(11.1$ s) and a smaller peak in the sea band at $f=0.1450 \mathrm{~Hz}(6.9 \mathrm{~s})$. This produces two infragravity peaks in the surf zone spectrum at $f=0.0078 \mathrm{~Hz}(128.2 \mathrm{~s})$ and $0.0234 \mathrm{~Hz}$ (42.7 s); albeit these peaks are smaller than the infragravity peak in tide 10 by more than a factor of 3 . 

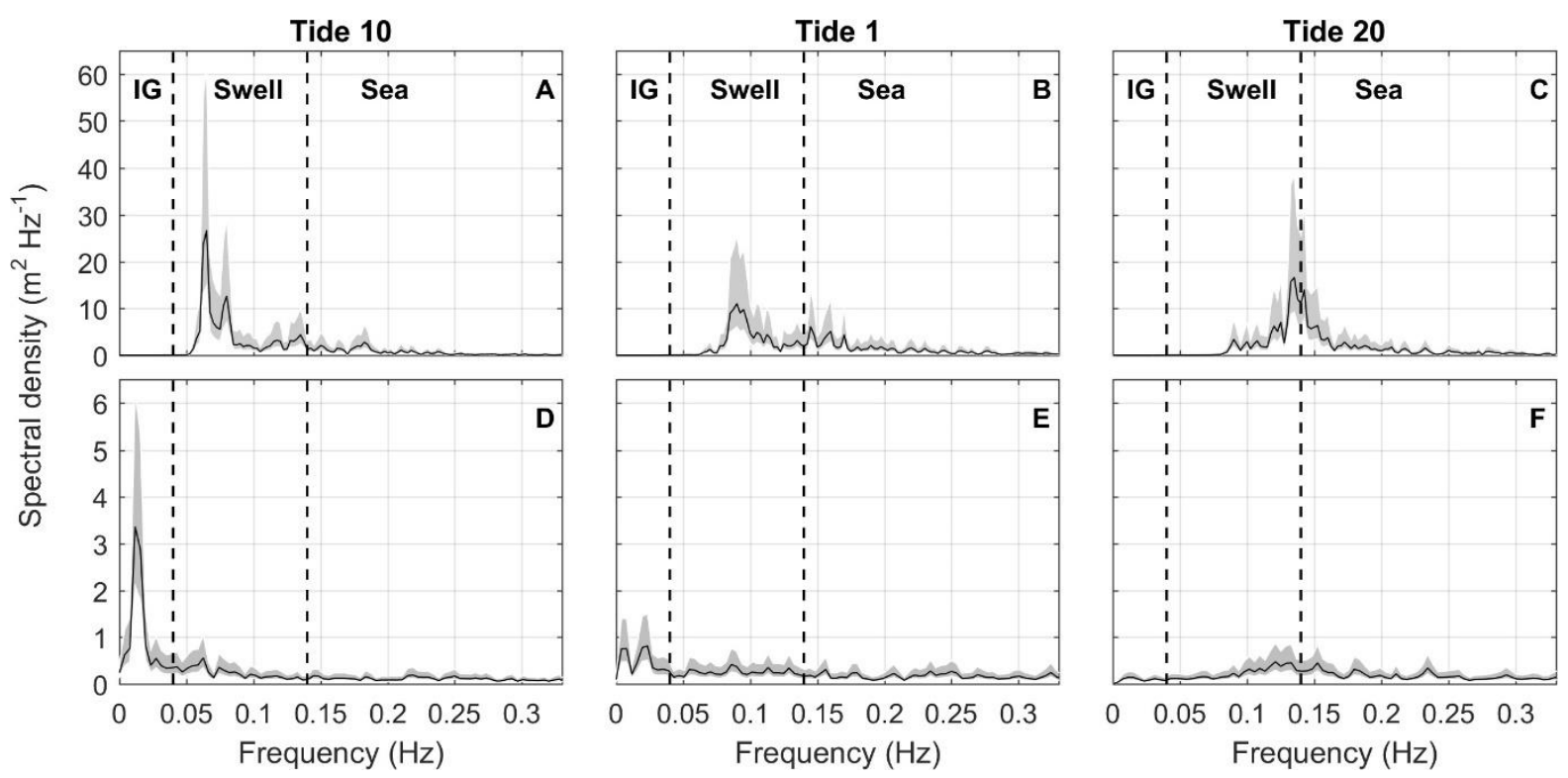

Fig. 8. Offshore wave spectra at the wave buoy (A-C) and surf zone wave spectra at $h \approx 2 \mathrm{~m}$ (D-F), for tides 10 (left panels), 1 (middle panels), and 20 (right panels). Shaded areas are 95\% confidence intervals.

With $H_{o}$ values of almost $3 \mathrm{~m}$, the entire instrument array was situated within the surf zone during all three tides, as evident by the constant linear decrease in $H_{S S}$ typical of a saturated surf zone (Fig. 9a-c). Maximum $H_{\text {inf }}$ values always occur at the shallowest sensor and reach $0.87 \mathrm{~m}$ during tide 10 which had the highest $T_{p}$ of $15.4 \mathrm{~s}$. This is a factor of 3 times larger than tide 20 during which $T_{p}$ was only $7.4 \mathrm{~s}$. Fig. 9d-f shows evidence of infragravity wave dissipation during all three tides with $F^{+}$exceeding $F^{-}$at all locations, and $F^{+}$decreasing shoreward with maximum values at the deepest sensor and minimum values at the shallowest sensor. The magnitude of $F^{+}$is considerably higher during the high period tides. For example, relative to tide $20, F^{+}$at $h \approx 3 \mathrm{~m}$ is larger by a factor of 3 during tide 1 , and by a factor of 5 during tide 10. Furthermore, maximum values of $F^{+}$during tide 20 are less than the minimum values during tides 10 and 1 .

Dissipation rates of the incoming and outgoing infragravity waves $\left(D^{+}\right.$and $D^{-}$, respectively) are shown in Fig. 9g-i and are calculated between sensors as $D^{ \pm}=\frac{1}{h} \frac{\Delta F^{ \pm}}{\Delta x}$, where $\Delta$ indicates a difference and $x$ is cross-shore location. Values of $D^{+}$tend to increase shoreward with maximum values occurring between the shallowest sensors for all tides. However, $D^{+}$is considerably larger when there is more energetic offshore forcing. For example, spatially averaged $D^{+}$for $h<3 \mathrm{~m}$ is higher by almost a factor of 5 during tide 10 compared to tide 20 . 
As a result of this, the difference in magnitude of $F^{+}$between the three tides is smaller at the shoreline than it is in deeper water. For example, at $h \approx 3 \mathrm{~m}, F^{+}$during tide 10 is $0.054 \mathrm{~m}^{3} \mathrm{~s}^{-1}$ more than tide 1 , which in turn is $0.042 \mathrm{~m}^{3} \mathrm{~s}^{-1}$ more than tide 20 . Whereas at $h \approx 1 \mathrm{~m}$ these numbers are $0.036 \mathrm{~m}^{3} \mathrm{~s}^{-1}$ and $0.022 \mathrm{~m}^{3} \mathrm{~s}^{-1}$, respectively.

As further evidence of this dissipation, bulk infragravity reflection coefficients (Fig. 9j-1) averaged across the array are $0.16,0.23$, and 0.15 for tides 10,1 , and 20 , respectively. Bulk reflection coefficients increase slightly towards the shore where, despite reaching their maximum, are well below 0.5. This implies that considerable dissipation of $F^{+}$, equal to > $50 \%$, occurs over the short and shallow cross-shore stretch between the shallowest sensor and the shoreline (typically $\sim 30 \mathrm{~m}$ ). The difference in $R^{2}$ at the shallowest sensor during the three tides can, at least partially, be attributed to differences in the swash zone beach slope. Tide 1, which had the highest shoreline $R^{2}$ of 0.43 , was during the spring tide phase when the swash zone was located further landward and characterized by steeper slopes close to the fore dunes. Whereas tide 20 was during the neap tide phase when the swash zone was situated further seaward where the foreshore slope is gentler, hence the smaller shoreline $R^{2}$ of 0.28 . 

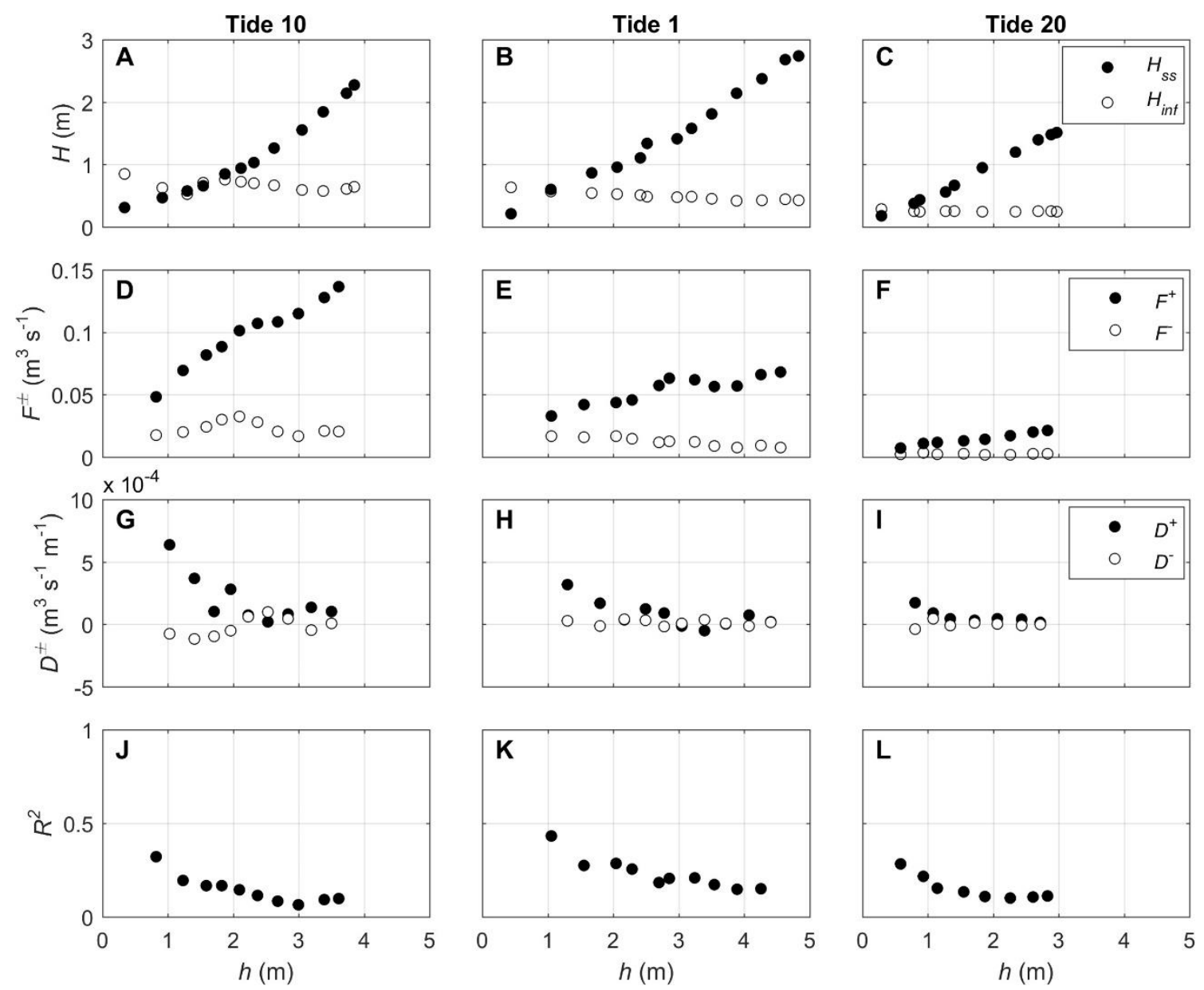

Fig. 9. Sea-swell $H_{s S}$ (dots) and infragravity $H_{\text {inf }}$ (circles) significant wave height (A-C), bulk incoming $F^{+}$(dots) and outgoing $F^{-}$(circles) infragravity energy flux (D-F), bulk incoming $D^{+}$(dots) and outgoing $D^{-}$(circles) infragravity dissipation rate (G-I), and bulk infragravity reflection coefficient $R^{2}$ (J-L), versus water depth $h$ for tides 10 (left panels), 1 (middle panels), and 20 (right panels).

To investigate the cross-shore structure of infragravity waves, as well as potential frequencydependence, a frequency-domain Complex Empirical Orthogonal Function (EOF) of the infragravity sea-surface elevation is implemented following Henderson et al. (2000). In this method, an eigenfunction analysis of the cross-spectral matrix at individual infragravity frequencies is performed with the dominant eigenfunction representing the dominant crossshore structure of infragravity waves at that frequency. For the examples presented here, the dominant eigenfunction accounted for between $72 \%$ and $96 \%$ of the variance summed over the array. Fig. 10 shows the EOF results and frequency-dependant reflection coefficients for three infragravity frequencies during the three example tides. These frequencies were chosen arbitrarily as representative low, medium, and high frequencies within the infragravity band. 
At the lowest frequency of $f=0.0078 \mathrm{~Hz}(128 \mathrm{~s})$ the non-dimensional amplitude $M$ of the dominant EOF displays a clear standing wave structure for all tides. The shoreward increase in $M$ at distances $<100 \mathrm{~m}$ indicate the presence of an antinode at the shoreline, with a second antinode at a distance of approximately $225 \mathrm{~m}$ and a node at around $100 \mathrm{~m}$, with a phase jump of $\pm \pi$ at the node. An (anti)nodal structure is also evident at $f=0.0195 \mathrm{~Hz}(51 \mathrm{~s}$ ), although less clear, but phase now increases more linearly shoreward. The pattern at $f=$ $0.0391 \mathrm{~Hz}(26 \mathrm{~s})$ is one of decreasing amplitude in the shoreward direction for all tides and phase increases are entirely linear, indicative of progressive waves with little or no shoreline reflection. The patterns shown by the EOFs agree well with the frequency-dependant reflection coefficients which, at each frequency, are similar for the three tides and average $( \pm$ one standard deviation) $0.45 \pm 0.09,0.21 \pm 0.05$, and $0.05 \pm 0.02$ for $0.0078 \mathrm{~Hz}, 0.0195 \mathrm{~Hz}$, and $0.0391 \mathrm{~Hz}$, respectively (Fig. 10g-i).
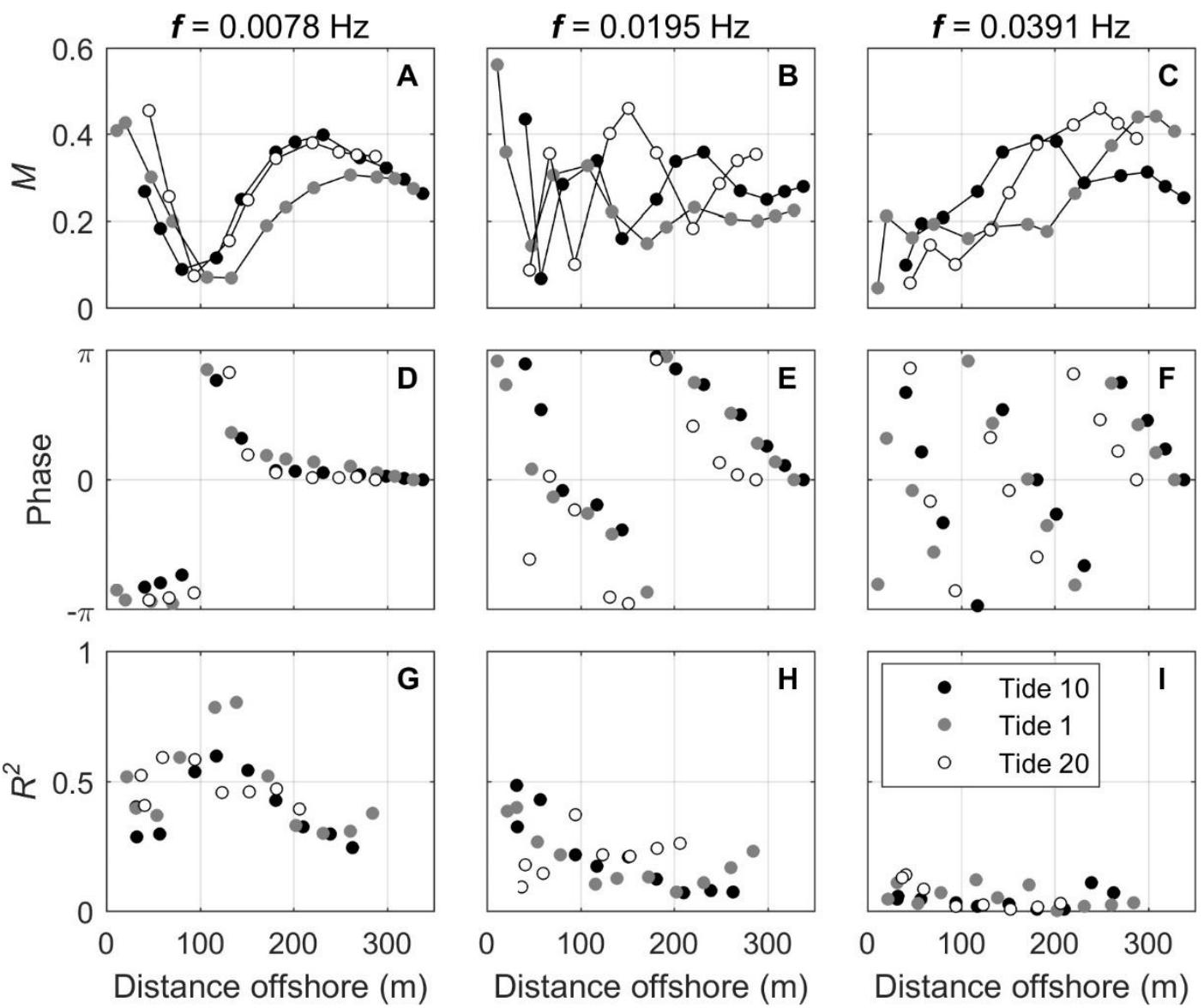

Fig. 10. Non-dimensional amplitude $M(\mathrm{~A}-\mathrm{C})$, phase (D-F), and reflection coefficients $R^{2}$ versus distance offshore for $f=0.0078 \mathrm{~Hz}$ (left panels), $f=0.0195 \mathrm{~Hz}$ (middle panels), and $f=0.0391 \mathrm{~Hz}$ (right panels). Black dots are tide 10, grey dots are tide 1, and circles are tide 20. $M$ and phase are associated with the dominant Empirical Orthogonal Function (EOF), 
computed following Henderson et al. (2000).

These observations imply that dissipation of infragravity waves is frequency-dependant, with high frequency waves dissipating more than low frequency waves. To demonstrate this further, the infragravity band is partitioned into three smaller bands; low $(0.005<f<0.017$ $\mathrm{Hz})$, medium $(0.017<f<0.028 \mathrm{~Hz})$, and high $(0.028<f<0.04 \mathrm{~Hz})$. At $h \approx 3 \mathrm{~m}$ during tide 10 , the ratio of $F^{+}$in the low frequency band to that in the high frequency band is 1.99 . Whereas at $h \approx 1 \mathrm{~m}$, increased dissipation in the high frequency band has increased this ratio to 7.95. During tide 20, energy in the low frequency infragravity band is less than that in the high frequency band at $h \approx 3 \mathrm{~m}$ with a ratio of 0.57 . Similar to tide 10 , however, this ratio increases shoreward to 1.06 at $h \approx 1 \mathrm{~m}$, indicative of high frequency dissipation. At the shallowest sensor, $>90 \%$ of the total $F^{-}$is within the low infragravity frequency band for the three tides. This implies that almost all of $F^{+}$remaining at frequencies $>0.017 \mathrm{~Hz}$ must have dissipated between the shallowest sensor and the shoreline.

Fig. 11 shows bulk $R$ values for the total infragravity band and the three partitioned infragravity bands during all 33 tides versus $\beta_{H}$ (Eq. 1). In calculating $\beta_{H}, H^{+}$is estimated as $H^{+}=4 \sqrt{\int_{l f}^{h f} E^{+}(f) d f}$, where $h f$ and $l f$ represent the high and low frequency cut-offs for each infragravity band, respectively, and $T$ is taken as the central wave period of each frequency band. For the total infragravity band (Fig. 11a), $R$ values are typically in the range $0.2-0.5$, placing them in a mild sloping regime, and increase with $\beta_{H}$ which is predominantly $<2$. Values of $R<0.4$ agree well with the theoretical curve of Van Dongeren et al. (2007); however, $R$ values $>0.4$ show evidence of a more gentle increase with $\beta_{H}$. A clear relationship between partitioned $R$ values and $\beta_{H}$ can be seen in Fig. 11b, with $R$ in the high frequency band corresponding to $\beta_{H}$ values less than 2 . Higher values of $R$ in the low and medium frequency bands correspond to typical $\beta_{H}$ values of $2<\beta_{H}<7$ and $1<\beta_{H}<3$, respectively. For the two higher frequency infragravity bands, $R$ values tend to increase with increasing $\beta_{H}$. However, $R$ in the low frequency band plateaus around 0.7 when $\beta_{H} \approx 3$, thus distinguishing the mild to steep sloping regime. The location of this transition implies that infragravity frequencies $>0.017 \mathrm{~Hz}$ are in the mild sloping regime and dissipate energy due to wave breaking, whereas frequencies $<0.017 \mathrm{~Hz}$ are more commonly in the steep sloping regime allowing for stronger reflection. It must be noted that $\beta_{H}$ is influenced by the 
bandwidth of the frequency range used in its calculation. Therefore, the comparison of $\beta_{H}$ for different size frequency bands (i.e., Fig. 11a and 11b) should be carried out with caution.
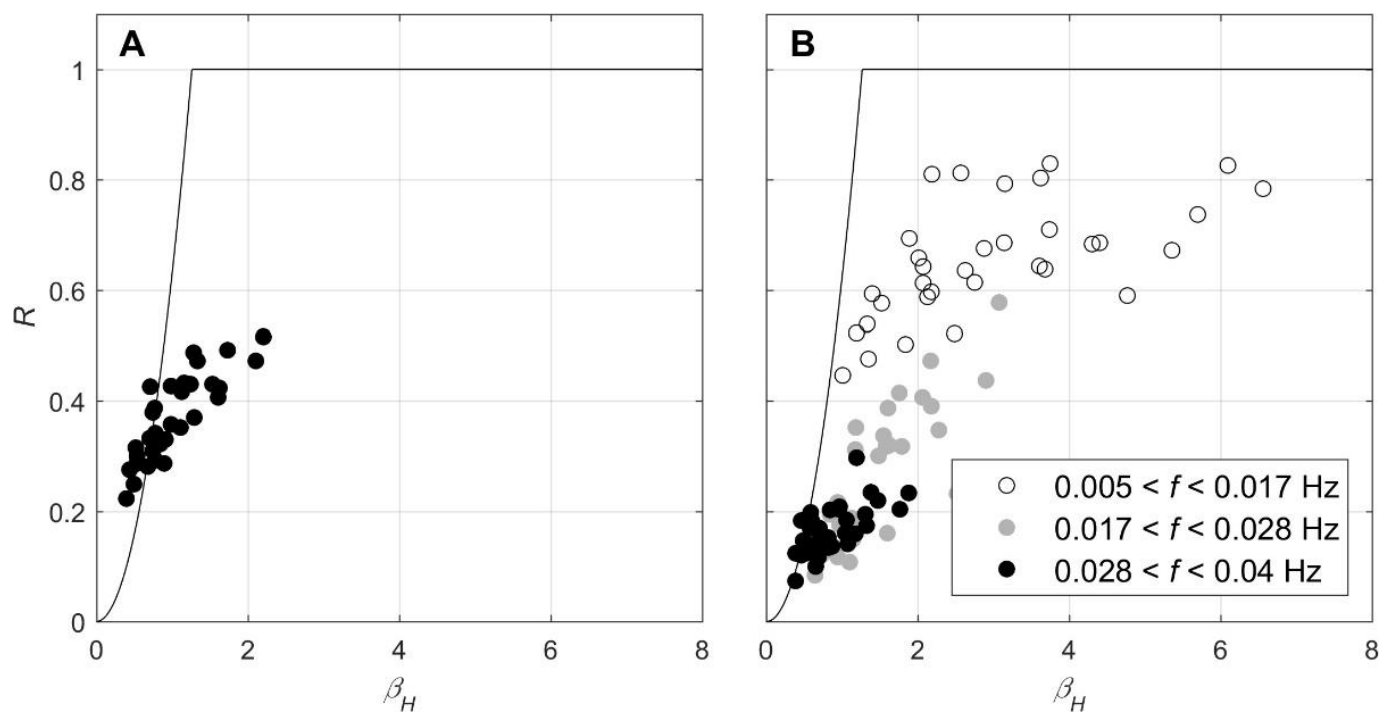

Fig. 11. Bulk amplitude reflection coefficients $R$ for the total infragravity band (A) and for partitioned infragravity bands (B) versus the normalized bed slope parameter $\beta_{H}$. The solid black lines are $\min \left(1, R=0.2 \pi \beta_{H}^{2}\right)$, following Van Dongeren et al. (2007).

\section{Discussion}

\subsection{Relationship with offshore forcing}

The infragravity waves measured during this study were well correlated with the wave conditions offshore, suggesting that they are driven by the local short wave regime rather than travelling from a distant source. The much stronger correlation between infragravity wave height and offshore swell waves rather than sea waves has been observed at other sites (e.g., Elgar et al., 1992; Okihiro et al., 1992; Ruessink, 1998).

Infragravity wave height is best predicted by using an independent variable that accounts for wave period. This is consistent with the findings of Stockdon et al. (2006) and Senechal et al. (2011) whilst studying infragravity runup, although a stronger prediction is obtained by using $H_{o}^{2} T_{p}$ rather than their parameter $\left(H_{o} L_{o}\right)^{1 / 2}$. The parameter $H_{o}^{2} T_{p}$ is proportional to the offshore energy flux and therefore has arguably better physical justification than $\left(H_{o} L_{o}\right)^{1 / 2}$. 
The stronger correlation between infragravity wave height close to shore and $H_{\text {swell }}$ or another a parameter that accounts for wave period is explained by longer period swells tending to have a narrower spectrum than shorter period wind-sea. To demonstrate this in the present study, the dimensionless bandwidth parameter (Longuet-Higgins, 1984), which provides a measure of the narrowness of the spectrum, was calculated and found to be positively correlated with $T_{p}$ with an $r^{2}$ of 0.51 . In bound wave theory, the strength of the coupling between pairs of sea-swell waves is stronger under narrow-banded conditions and when the two frequencies are close together, whereas under broad-banded conditions energy transfers are weaker and spread over a larger range of frequencies (Hasselmann, 1962; Longuet-Higgins and Stewart, 1962). Stronger coupling and higher levels of infragravity energy under narrow-banded conditions has been demonstrated by field (e.g., Elgar and Guza, 1985), laboratory (e.g., De Bakker et al., 2015), and modelling (e.g., Okihiro et al., 1992; Norheim et al., 1998) studies.

Further support for bound wave theory is provided by the negative correlation between the infragravity waves and the short wave envelope. The observed time lag of the infragravity wave behind the short wave envelope was also observed by List (1991) and Masselink (1995), and has been shown to be a necessary condition for the transfer of energy from short waves to shoaling bound waves (e.g., Janssen et al., 2003; Battjes et al., 2004). The bound infragravity waves appear to be released, as indicated by a change from negative to positive correlations with the short wave envelope, not at the initiation of short wave breaking but further into the surf zone at $h / h_{b} \approx 0.7$, where all short waves are likely to have broken and the 'offshore' wave groups are destroyed.

The best fit linear slope of infragravity wave height to $H_{o}$ is steeper than that measured by De Bakker et al. (2014) on a dissipative beach in the Netherlands with similar wave heights, but much smaller wave periods. Indeed, the maximum offshore wave period measured during their study was less than the minimum wave period during any of the high tides in the present study. However, it must be noted that De Bakker et al. (2014) observed some saturation for $H_{o}>3 \mathrm{~m}$ which would act to lower the slope of the linear fit line.

In the present dataset, the swell frequency band accounts for an average of $73 \%$ of the total short wave energy offshore and $T_{p}$ is in the swell band for all high tides. Field campaigns on limited fetch coastlines, such as the Netherlands, observe $T_{p}$, and presumably the bulk of the 
short wave energy, in the sea frequency band. This likely plays a role in the smaller infragravity wave heights and responses to $H_{o}$ reported on these coastlines, and possibly the likelihood of saturation occurring.

Whilst the infragravity wave height increases with offshore forcing without signs of saturation, infragravity dissipation rates in the surf zone also increase and amplification of the infragravity wave height from the deepest sensor to the shallowest decreases. That is to say, as the offshore forcing intensifies, the corresponding increase in infragravity wave height and energy flux reaching the shoreline becomes progressively smaller. In fact, had the largest amplification of the infragravity wave height that occurred during low offshore wave forcing also occurred during the most energetic offshore conditions, the shoreline infragravity wave height would be $2.67 \mathrm{~m}$ rather than the $1.02 \mathrm{~m}$ that was observed. Similar observations were found by Fiedler et al. (2015) on a fetch-unlimited beach and, interestingly, the largest infragravity wave height they measured with $H_{o}>7 \mathrm{~m}$ was around $1.2 \mathrm{~m}$; only $0.18 \mathrm{~m}$ more than that measured in the present study with $H_{o}$ less than half the size.

\subsection{Infragravity dissipation}

Consistent with previous field studies (e.g., Henderson et al., 2000; Guedes et al., 2013; De Bakker et al., 2014), the infragravity dissipation observed is frequency-dependant with more energy being conserved at lower frequencies. Furthermore, dissipation rates are higher in the inner surf zone and reflection coefficients indicate that a significant amount of dissipation occurs between the shallowest sensor and the shoreline. Relating $R$ to $\beta_{H}$ places infragravity frequencies $>0.017 \mathrm{~Hz}$ in the mild sloping regime suggesting that dissipation at these frequencies, at least at the shoreline, is due to infragravity wave breaking. The transition between mild and steep sloping regime at $\beta_{H} \approx 3$ is higher than $\beta_{H} \approx 1.25$ observed by Van Dongeren et al. (2007), but consistent with the field measurements of De Bakker et al. (2014); however, as the aforementioned study acknowledged, obtaining measurements on the edge of the swash zone is more problematic in the field compared to the laboratory, especially when using an array of pressure sensors to estimate reflection.

In contrast to the dissipation observed in the present study, the dissipation observed by Thomson et al. (2006), which was ascribed to non-linear energy transfers, was strongest in 
the middle of the surf zone and decreased closer to shore where there was almost complete reflection. Interestingly, however, Thomson et al. (2006) observed the transition from increasing to decreasing $F^{+}$at a normalized surf zone (their $x_{S Z}$ ) position of 0.7 , as was found in the present study. Baldock (2012) points out that, during energetic offshore conditions $\left(H_{O}\right.$ and $T_{p}$ ), the larger short waves may not be true shallow water waves at the time of breaking and that, until the short waves are in shallow water, the bound infragravity wave does not satisfy the free wave dispersion relationship required for its release. The conditions required for short waves to be in shallow water when they break can be parameterized in terms of the deep water short wave steepness (Baldock and O'Hare, 2004) as $\frac{H_{O}}{L_{o}} \leq 0.016 \gamma_{b}$. In the present study, the largest short waves broke as shallow water waves for only 6 out of the 33 high tides, corresponding to lower values of $H_{o}^{2} T_{p}$. Based on this theory, a possible explanation for the release and onset of infragravity wave dissipation at $h / h_{b} \approx 0.7$ is that the bound waves are still being forced past the breakpoint of the largest short waves and into the surf zone until shallow water wave conditions are satisfied.

\subsection{Non-linear energy transfer}

Bispectral analysis, first introduced by Hasselmann et al. (1963), is performed on the data to examine the possible role of non-linear energy transfer in the observed infragravity dissipation. The bispectrum $B_{f_{1}, f_{2}}$ describes triad interactions between frequencies $f_{1}$ and $f_{2}$, and their sum frequency $f_{3}=f_{1}+f_{2}$. A detailed description of bispectral analysis is provided by, for example, Elgar and Guza (1985) and Collis et al. (1998). The imaginary part of the bispectrum is used to examine the direction and magnitude of energy transfers; positive interactions indicate a transfer of energy from $f_{1}$ and $f_{2}$ to their sum $f_{3}$, whereas negative interactions indicate a transfer of energy from $f_{3}$ to $f_{1}$ and $f_{2}$. In calculating the bispectrum, longer time series of 16384 were used and bipectral estimates were averaged to give a frequency resolution of $0.0117 \mathrm{~Hz}$ and 186 degrees of freedom. This was necessary to lower the 95\% significance threshold on bicoherence to 0.18 (Kim and Powers, 1979).

Fig. 12 shows the imaginary part of the bispectrum at three cross-shore locations during tide 10; the example tide with the highest $T_{p}$ value. In the middle of the surf zone at $h / h_{b}=0.44$ (Fig. 12a), a positive (red) interaction at $B(0.065,0.065)$ indicates that, despite being well within the surf zone, energy is still being transferred from the spectral peak to its first harmonic at $f_{3}=0.130 \mathrm{~Hz}$, where a weaker positive interaction shows that energy is being 
transferred to the second harmonic also. A negative (blue) interaction near $B(0.047,0.012)$ is associated with a transfer of energy from $f_{3}=0.59 \mathrm{~Hz}$, close to the peak frequency, to $f_{1}=$ $0.047 \mathrm{~Hz}$ and to the infragravity band at $f_{2}=0.012 \mathrm{~Hz}$.

Further shoreward at $h / h_{b}=0.27$ (Fig. 12b), the positive interaction involving the spectral peak has weakened significantly (note change in colour scale), whereas the negative interaction transferring energy to the infragravity band remains strong. A positive infragravity-infragravity interaction has now emerged at around $B(0.023,0.012)$ transferring energy from these low infragravity frequencies to the higher infragravity frequency $f_{3} \approx$ $0.035 \mathrm{~Hz}$.

Very close to shore at $h / h_{b}=0.11$ (Fig. 12c), two positive interactions exist involving the infragravity spectral peak. The peak-peak interaction at $B(0.012,0.012)$ indicates a transfer of energy to a higher infragravity harmonic at $f_{3}=0.024 \mathrm{~Hz}$, which subsequently appears to be transferred to the next harmonic close to the boundary with the sea-swell band.

Similar trends as seen in Fig. 12 are present during most tides, although interactions weaken with decreasing energy offshore and are spread out over a larger range of frequencies when the offshore wave period is lower and the spectrum is more broad-banded. This is consistent with past studies such as Elgar and Guza (1985), Norheim et al. (1998), and De Bakker et al. (2015).

The results of the bispectral analysis suggest that non-linear energy transfers from infragravity to sea-swell frequencies do not play an important role in the observed infragravity energy loss. Rather, transfers of infragravity energy to higher frequencies tend to occur in shallow water as an energy transfer to higher harmonics of the infragravity wave. This transfer of energy to higher infragravity harmonics is analogous to the shoaling process of sea-swell waves outside the surf zone and ultimately supports the steepening and eventual breaking of infragravity waves close to shore.

Due to the lack of co-located pressure and velocity data, bispectra were calculated using the total wave signal as opposed to the decomposed incoming wave signal. This has been shown to cause a decrease in levels of bicoherence (Elgar and Guza, 1985; De Bakker et al., 2015); however, general trends in the bispectra are relatively unaffected, especially with narrowbanded spectra when the coupling between frequencies is strong, such as that shown in Fig. 12. 

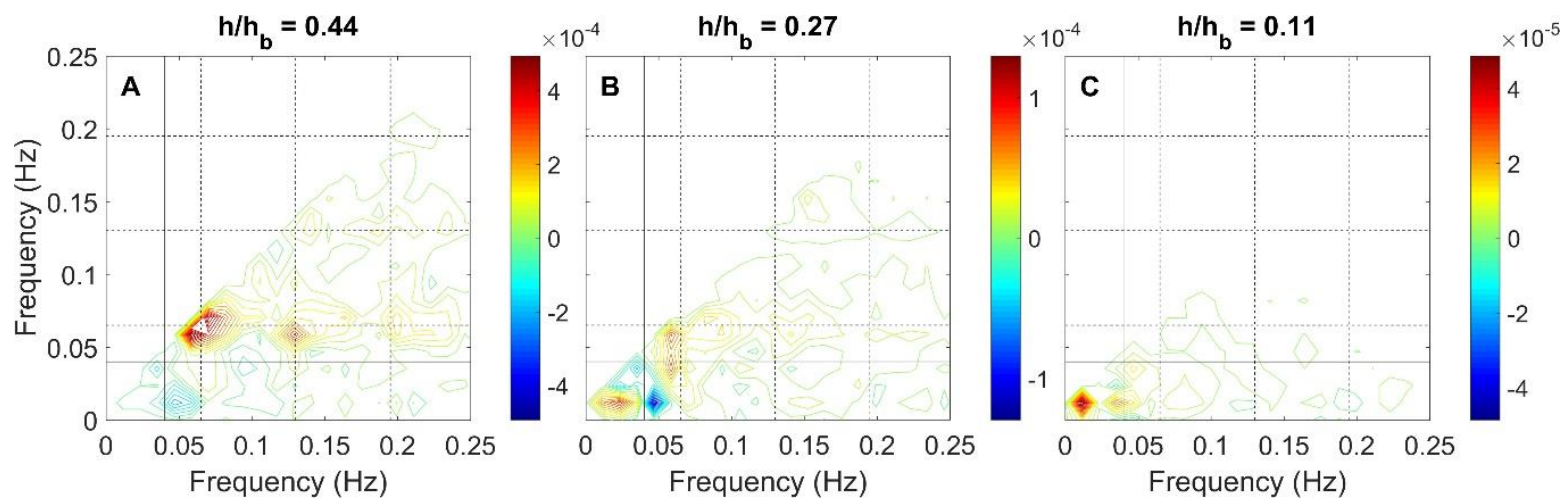

Fig. 12. Imaginary part of the bispectrum from tide $10\left(H_{o}=2.96 \mathrm{~m}, T_{p}=15.4 \mathrm{~s}\right)$ at three normalized surf zone $h / h_{b}$ locations; $0.44(\mathrm{~A}), 0.27(\mathrm{~B})$, and $0.11(\mathrm{C})$. Where the corresponding bicoherence is below the $95 \%$ significant threshold of 0.18 , bispectral estimates are set to zero. Solid black lines indicate the transition between infragravity and sea-swell frequency bands. Dashed lines indicate the offshore peak period and its higher harmonics.

\section{Conclusion}

Observations from a dissipative beach during a wide range of offshore forcing conditions demonstrate the difference in nearshore infragravity wave characteristics under contrasting sea and swell wave conditions. Infragravity waves are shown to be generated predominantly in accordance with bound wave theory and are released as free waves just seaward of the mid-surf zone position. Infragravity wave height at the shoreline is well correlated with $H_{o}$, but a more accurate prediction is obtained by using $H_{o}^{2} T_{p}$, which represents the offshore energy flux. Strong infragravity dissipation is observed in the surf zone and the rate of this dissipation increases with offshore forcing, thus showing a possible sign of proto-saturation of the infragravity waves. Dissipation and consequent shoreline reflection is highly frequency-dependant as waves with frequencies $<0.017 \mathrm{~Hz}$ display a cross-shore standing wave structure and $R^{2} \approx 0.4$, whereas waves with frequencies $>0.028 \mathrm{~Hz}$ are onshore progressive and undergo almost complete dissipation $\left(R^{2}<0.1\right)$. The relationship between $R$ and $\beta_{H}$ suggests that wave breaking is the dominant dissipation mechanism at the shoreline as all but the lowest frequency waves are in the mild sloping regime. Non-linear energy transfers in shallow water occur between the infragravity peak and its higher harmonics, thus providing further support for infragravity wave breaking. 


\section{Acknowledgements}

The authors would like to thank Kit Stokes, Sam Prodger, Tim Poate, Erwin Bergsma and Olivier Burvingt for their assistance in the field. Technical support was provided by Peter Ganderton. Wave buoy data was provided by the Plymouth Coastal Observatory. Comments made by two anonymous reviewers led to significant improvements to the manuscript.

\section{References}

Ardhuin, F., Rawat, A. and Aucan, J. 2014. A numerical model for free infragravity waves: Definition and validation at regional and global scales. Ocean Modelling, 77, 20-32.

Aucan, J. and Ardhuin, F. 2013. Infragravity waves in the deep ocean: An upward revision. Geophysical Research Letters, 40, 3435-3439. 10.1002/grl.50321

Baldock, T.E. 2012. Dissipation of incident forced long waves in the surf zone - implications for the concept of "bound" wave release at short wave breaking. Coastal Engineering, 60, 276-285. doi:10.1016/j.coastaleng.2011.11.002

Baldock, T.E. and Huntley, D.A. 2002. Long-wave forcing by the breaking of random gravity waves on a beach. Proceedings of the Royal Society of London A, 458, 2177-2201.

Baldock, T.E. and O'Hare, T.J. 2004. Energy transfer and dissipation during surf beat conditions. Proceedings of the $29^{\text {th }}$ Conference on Coastal Engineering. World Scientific, New Jersey. 10.1142/9789812701916_0096

Battjes, J.A., Bakkenes, H.J., Janssen, T.T. and van Dongeren, A.R. 2004. Shoaling of subharmonic gravity waves. Journal of Geophysical Research, 109, C02009.

$\underline{10.1029 / 2003 J C 001863}$

Biésel, F. 1952. Équations générales au second ordre de la houle irrégulière. La Houille Blanche, 7, 372-376. 
Collis, W.B., White, P.R. and Hammond, J.K. 1998. Higher-order spectra: the bispectrum and trispectrum. Mechanical Systems and Signal Processing, 12, 375-394.

doi:10.1006/mssp.1997.0145

Contardo, S. and Symonds, G. 2013. Infragravity response to variable wave forcing in the nearshore. Journal of Geophysical Research, 118, 7095-7106. 10.1002/2013JC009430

Crawford, W., Ballu, V., Bertin, X. and Karpytchev, M. 2015. The sources of deep ocean infragravity waves observed in the North Atlantic Ocean. Journal of Geophysical Research, 120, 5120-5133. 10.1002/2014JC010657

De Bakker, A.T.M., Tissier, M.F.S. and Ruessink, B.G. 2014. Shoreline dissipation of infragravity waves. Continental Shelf Research, 72, 73-82. doi:10.1016/j.csr.2013.11.013

De Bakker, A.T.M., Herbers, T.H.C., Smit, P.B., Tissier, M.F.S. and Ruessink, B.G. 2015. Nonlinear infragravity-wave interactions on a gently sloping laboratory beach. Journal of Physical Oceanography, 45, 589-605. http://dx.doi.org/10.1175/JPO-D-14-0186.1

De Bakker, A.T.M., Tissier, M.F.S. and Ruessink, B.G. 2016. Beach steepness effects on nonlinear infragravity-wave interactions: a numerical study. Journal of Geophysical Research, 121, 554-570. 10.1002/2015JC011268

Elgar, S. and Guza, R.T. 1985. Observations of bispectra of shoaling surface gravity waves. Journal of Fluid Mechanics, 161, 425-448. https://doi.org/10.1017/S0022112085003007

Elgar, S., Herbers, T.H.C., Okihiro, M., Oltman-Shay, J. and Guza, R.T. 1992. Observations of infragravity waves. Journal of Geophysical Research, 97, 15573-15577.

$\underline{10.1029 / 92 J C 01316}$

Fiedler, J.W., Brodie, K.L., McNinch, J.E. and Guza, R.T. 2015. Observations of runup and energy flux on a low-slope beach with high-energy, long-period ocean swell. Geophysical Research Letters, 42, 9933-9941. 10.1002/2015GL066124 
Gaillard, P., Gauthier, M. and Holly, F. 1980. Method of analysis of random wave experiments with reflecting coastal structures. Proceedings of the $17^{\text {th }}$ Conference on Coastal Engineering. ASCE, New York. http://dx.doi.org/10.9753/icce.v17.\%25p

Garrett, C.J.R. and Toulany, B. 1981. Variability of the flow through the Strait of Belle Isle. Journal of Marine Research, 39, 163-189.

Guedes, R.M.C., Bryan, K.R. and Coco, G. 2013. Observations of wave energy fluxes and swash motions on a low-sloping, dissipative beach. Journal of Geophysical Research, 118, 3651-3669. 10.1002/jgrc.20267

Guza, R.T. and Thornton, E.B. 1982. Swash oscillations on a natural beach. Journal of Geophysical Research, 87, 483-491. 10.1029/JC087iC01p00483

Guza, R.T. and Thornton, E.B. 1985. Observations of surf beat. Journal of Geophysical Research, 90, 3161-3172. 10.1029/JC090iC02p03161

Hasselmann, K. 1962. On the non-linear energy transfer in a gravity-wave spectrum: Part 1. General theory. Journal of Fluid Mechanics, 12, 481-500.

http://dx.doi.org/10.1017/S0022112062000373

Hasselmann, K., Munk, W. and MacDonald, G. 1963. Bispectra of ocean waves. In Time Series Analysis, M. Rosenblatt (Ed.). John Wiley, New York. pp. 125-139.

Henderson, S.M. and Bowen, A.J. 2002. Observations of surf beat forcing and dissipation. Journal of Geophysical Research, 107, 3193. 10.1029/2000JC000498

Henderson, S.M., Elgar, S. and Bowen, A.J. 2000. Observations of surf beat propagation and energetics. Proceedings of the $27^{\text {th }}$ Conference on Coastal Engineering. ASCE, New York. http://dx.doi.org/10.1061/40549(276)109

Henderson, S.M., Guza, R.T., Elgar, S., Herbers, T.H.C. and Bowen, A.J. 2006. Nonlinear generation and loss of infragravity wave energy. Journal of Geophysical Research, 111, C12007. 10.1029/2006JC003539 
Inch, K., Davidson, M., Masselink, G. and Russell, P. 2017. Correcting wave reflection estimates in the coastal zone. Coastal Engineering, 119, 65-71.

http://dx.doi.org/10.1016/j.coastaleng.2016.09.004

Janssen, T.T., Battjes, J.A. and Van Dongeren, A.R. 2003. Long waves induced by shortwave groups over a sloping bottom. Journal of Geophysical Research, 108, 3252. $\underline{10.1029 / 2002 J C 001515}$

Kim, Y. and Powers, E. 1979. Digital bispectral analysis and its applications to nonlinear wave interactions. IEEE Transactions on Plasma Science, 7, 120-131.

$\underline{10.1109 / T P S .1979 .4317207}$

Lin, Y.H. and Hwung, H.H. 2012. Infra-gravity wave generation by the shoaling wave groups over beaches. China Ocean Engineering, 26, 1-18.

Lippmann, T.C., Herbers, T.H.C. and Thornton, E.B. 1999. Gravity and shear wave contributions to nearshore infragravity motions. Journal of Physical Oceanography, 29, 231239. http://dx.doi.org/10.1175/1520-0485(1999)029<0231:GASWCT>2.0.CO;2

List, J.H. 1991. Wave groupiness variations in the nearshore. Coastal Engineering, 15, 475496. doi:10.1016/0378-3839(91)90024-B

Longuet-Higgins, M.S. and Stewart, R.W. 1962. Radiation stress and mass transport in gravity waves with applications to 'surf beats'. Journal of Fluid Mechanics, 13, 481-504. $\underline{10.1017 / S 0022112062000877}$

Longuet-Higgins, M.S. 1984. Statistical properties of wave groups in a random sea state. Philosophical Transactions of the Royal Society of London Series A, 312, 219-250.

Masselink, G. 1995. Group bound long waves as a source of infragravity energy in the surf zone. Continental Shelf Research, 15, 1525-1547. doi:10.1016/0278-4343(95)00037-2 
Miles, J. and Thorpe, A. 2015. Bedform contributions to cross-shore sediment transport on a dissipative beach. Coastal Engineering, 98, 65-77. doi:10.1016/j.coastaleng.2015.01.007

Norheim, C.A., Herbers, T.H.C. and Elgar, S. 1998. Nonlinear evolution of surface wave spectra on a beach. Journal of Physical Oceanography, 28, 1534-1551.

http://dx.doi.org/10.1175/1520-0485(1998)028<1534:NEOSWS>2.0.CO;2

Nutall, A.H. 1971. Spectral estimation by means of overlapped FFT processing of windowed data. Naval Underwater Systems Center (NUSC) Report No. 4169. New London, Connecticut.

Okihiro, M., Guza, R.T. and Seymour, R.J. 1992. Bound infragravity waves. Journal of Geophysical Research, 97, 11453-11469. 10.1029/92JC00270

Poate, T., Masselink, G., Russell, P. and Austin, M. 2014. Morphodynamic variability of high-energy macrotidal beaches, Cornwall, UK. Marine Geology, 350, 97-111. doi:10.1016/j.margeo.2014.02.004

Pomeroy, A., Lowe, R., Symonds, G., van Dongeren, A. and Moore, C. 2012. The dynamics of infragravity wave transformation over a fringing reef. Journal of Geophysical Research, 117, C11022. 10.1029/2012JC008310

Raubenheimer, B., Elgar, S. and Guza, R.T. (1998) Estimating wave heights from pressure measured in sand bed. Journal of Waterway, Port, Coastal, and Ocean Engineering, 124, 151154. http://dx.doi.org/10.1061/(ASCE)0733-950X(1998)124:3(151)

Roelvink, D., Reniers, A., van Dongeren, A., van Thiel de Vries, J., McCall, R. and Lescinski, J. 2009. Modelling storm impacts on beaches, dunes and barrier islands. Coastal Engineering, 56, 1133-1152. doi:10.1016/j.coastaleng.2009.08.006

Ruessink, B.G. 1998. The temporal and spatial variability of infragravity energy in a barred nearshore zone. Continental Shelf Research, 18, 585-605. doi:10.1016/S0278$\underline{4343(97) 00055-1}$ 
Ruessink, B.G., Kleinhans, M.G. and van den Beukel, P.G.L. 1998. Observations of swash under highly dissipative conditions. Journal of Geophysical Research, 103, 3111-3118. $\underline{10.1029 / 97 J C 02791}$

Ruggiero, P., Holman, R.A. and Beach, R.A. 2004. Wave run-up on a high-energy dissipative beach. Journal of Geophysical Research, 109, C06025. 10.1029/2003JC002160

Ruju, A., Lara, J.L. and Losada, I.J. 2012. Radiation stress and low-frequency energy balance within the surf zone: a numerical approach. Coastal Engineering, 68, 44-55. doi:10.1016/j.coastaleng.2012.05.003

Russell, P.E. 1993. Mechanisms for beach erosion during storms. Continental Shelf Research, 13, 1243-1265. doi:10.1016/0278-4343(93)90051-X

Senechal, N., Coco, G., Bryan, K.R. and Holman, R.A. 2011. Wave runup during extreme storm conditions. Journal of Geophysical Research, 116, C07032. 10.1029/2010JC006819

Sheremet, A., Guza, R.T., Elgar, S. and Herbers, T.H.C. 2002. Observations of nearshore infragravity waves: seaward and shoreward propagating components. Journal of Geophysical Research, 107, C8. 10.1029/2001JC000970

Stockdon, H.F., Holman, R.A., Howd, P.A. and Sallenger Jr., A.H. 2006. Empirical parameterization of setup, swash, and runup. Coastal Engineering, 53, 573-588. doi:10.1016/j.coastaleng.2005.12.005

Symonds, G., Huntley, D. and Bowen, A.J. 1982. Two-dimensional surf beat: long wave generation by a time-varying breakpoint. Journal of Geophysical Research, 87, 492-498. 10.1029/JC087iC01p00492

Tissier, M., Bonneton, P., Michallet, H. and Ruessink, G. 2015. Infragravity-wave modulation of short-wave celerity in the surf zone. Journal of Geophysical Research, 120, 6799-6814. 10.1002/2015JC010708 
Thomson, J., Elgar, S., Raubenheimer, B., Herbers, T.H.C. and Guza, R.T. 2006. Tidal modulation of infragravity waves via nonlinear energy losses in the surfzone. Geophysical Research Letters, 33, L05601. 10.1029/2005GL025514

Thornton, E.B. and Guza, R.T. 1982. Energy saturation and phase speeds measured on a natural beach. Journal of Geophysical Research, 87, 9499-9508. 10.1029/JC087iC12p09499

Van Dongeren, A., Battjes, J., Janssen, T., van Noorloos, J., Steenhauer, K., Steenbergen, G. and Reniers, A. 2007. Shoaling and shoreline dissipation of low-frequency waves. Journal of Geophysical Research, 112, C02011. 10.1029/2006JC003701

Van Dongeren, A., Lowe, R., Pomeroy, A., Trang, D.M., Roelvink, D., Symonds, G. and Ranasinghe, R. 2013. Numerical modelling of low-frequency wave dynamics over a fringing coral reef. Coastal Engineering, 73, 178-190. doi:10.1016/j.coastaleng.2012.11.004

Van Thiel de Vries, J.S.M., van Gent, M.R.A., Walstra, D.J.R. and Reniers, A.J.H.M. 2008. Analysis of dune erosion processes in large-scale flume experiments. Coastal Engineering, 55, 1028-1040. doi:10.1016/j.coastaleng.2008.04.004 